\title{
Synthesis and structural properties of Mo-S-N sputtered coatings
}

Kaushik Hebbar Kannur ${ }^{1,2 *}$, Talha Bin Yaqub ${ }^{2}$, Teodor Huminiuc ${ }^{3}$, Tomas Polcar ${ }^{3}$, Christophe Pupier $^{1}$, Christophe Heau ${ }^{1}$, Albano Cavaleiro ${ }^{2}$

${ }^{1}$ IREIS-HEF Group, Avenue Benoit Fourneyron, CS 42077-42162 Andrezieux-Boutheon, France

${ }^{2}$ SEG-CEMMPRE, Department of Mechanical Engineering, University of Coimbra, Rua Luís Reis Santos, 3030-788 Coimbra, Portugal.

${ }^{3}$ nCATS, University of Southampton, University Road, Southampton SO17 1BJ, UK

*Corresponding author: Tel.+33767879725, E-mail address: khebbarkannur.ireis@hef.fr 


\section{Abstract:}

Transition-metal-dichalcogenide coatings provide low friction because of characteristic low shear strength along the basal plane of the lamellar structure; however, the material can easily degrade through exfoliation and poor adhesion to the metallic substrates. In this work, an innovative approach was employed to improve the coating's adhesion. A secondary plasma source was used during deposition to generate an additional charged particle flux which was directed to the growing film independently of the magnetron cathode. Therefore, Mo-S-N solid lubricant films were deposited by DCMS from a single molybdenum disulphide $\left(\mathrm{MoS}_{2}\right)$ target in a reactive atmosphere. Nitrogen was introduced during the deposition with increasing partial pressures, resulting in a high $\mathrm{N}_{2}$ content in the doped films (37 at. \%). The variation in incident ion energy and flux of energetic species bombarding the growing film allows for the control of the S/Mo ratio through selective re-sputtering of sulphur from the film. The S/Mo ratio was progressively increased to the range of 1.2-1.8, having gradient from metallic layer upto-the lubricious sulphide. Combining the ion bombardment with nitrogen incorporation, cohesive critical load (Lc1) reached $38 \mathrm{~N}, 10$ times more than $\mathrm{MoS}_{2}$ coating. Observation using HRTEM revealed an amorphous structure and strong bonding with the substrate.

Keywords: transition metal dichalcogenides; solid lubricant coatings; DC magnetron sputtering; Mo-S-N coatings; nitrogen-doped TMD coatings. 


\section{INTRODUCTION}

Transition metal dichalcogenides (TMDs): sulphides, selenides or tellurides of tungsten or molybdenum are well known for their lubricating properties [1]. Hexagonal $\mathrm{MoS}_{2}$ and $\mathrm{WS}_{2}$ are compounds with unique characteristics originating from an extreme degree of crystalline anisotropy and, due to this, the TMDs have gained considerable attention in the research community for a variety of mechanical, electronic and optical applications [2-5]. Despite the greater resistance to high temperature oxidation of $\mathrm{WS}_{2}$ [6], $\mathrm{MoS}_{2}$ has been more widely studied due to its lower cost and lubricating performance in a vacuum and dry atmosphere, Initially, $\mathrm{MoS}_{2}$ coatings were deposited by burnishing [7], electrochemical process [8] and plasma vapour deposition [7-12] techniques. Following the development of magnetron sputtering techniques, further research efforts have been carried out to deposit these coatings with bespoke crystalline and chemical properties, which ultimately lead to improvements in the tribological performance [10]. However, sputtered $\mathrm{MoS}_{2}$ films exhibit porous morphology which reduces their load-bearing capacity, oxidation resistance and adhesion to the substrates and adversely affect the mechanical and easy shear properties [13,14]. The possible solution to overcome these issues is the addition of a third element to the coatings, which can disrupt the crystal structure and the growth of weakly-bound pure chalcogenides to enhance the compactness and oxidation resistance. TMD have been doped with different metals such as Ti [15-21], Ag [22], Al [19], Co [22], Au [23-25], $\mathrm{Cr}$ [22], Fe [26], Ni [11,22,25,27], Pb [25,28], Pt [22], Ta [22,29], W [22], Zr [30]. Regardless of the beneficial results [20], the industrial implementation of metal doped $\mathrm{MoS}_{2}$ coating is limited (e.g., MoST by Teer coatings [20]) due to either the rapid oxidation of tribofilms into metal oxides [31] or the detrimental effects of hard metal particles (e.g. Ti) abrasion of tribofilms [32]. Moreover, economics do not favour the use of metal doping: metal doping requires a minimum of two targets for the PVD systems (i.e. one for metal and one for TMDs), consequently, increasing costs for the processing and development.

Alternatively, Non-metal doping (e.g. N and C) has attracted both researchers and industry. Carbon introduction in TMDs was first reported by Voevodin et.al. [33]. To deposit TMD-C coatings using only one cathode, the carbon incorporation was achieved 
by reactive sputtering, with precursor gases such as $\mathrm{CH}_{4}$ or $\mathrm{C}_{2} \mathrm{H}_{2}$. In such cases, hydrogen can react with the chalcogen not only changing the stoichiometry of $\mathrm{MoS}_{2}$ but also acts as a contamination source [34].

Nitrogen doping, on the other hand, has been rarely explored but seems a promising strategy for changing the structure of the coatings. With the use of only one cathode (with the TMD target) allows reducing the production complexity and costs, providing the advantage of avoiding the contamination by other elements (no precursor gas) [35]. Moreover, when compared to carbon, a small amount of nitrogen can be sufficient to achieve a dense amorphous coating, further reducing the operating costs [36]. In order to grow mechanically stable coatings, it is important to prevent the easily sheared planes from forming or by reducing the crystallinity of the softer phase. This can easily be achieved by nitrogen doping [37]. Mutafov et al. [38] reported that magnetron sputtered amorphous W-S-N films exhibit a low coefficient of friction (COF) high load-bearing capacity and good wear resistance. The atomic level structure and bonding arrangements in amorphous W-S-N have been described by Isaeva et. al. [36]. They also reported that, during sliding, nitrogen is released from the contact zone in a gaseous form (e.g. $\mathrm{N}_{2}, \mathrm{NO}_{2}$ ) without disturbing the formation of tribofilms. Zhang et. al. [31] reported that the incorporation of a small amount of nitrogen into $\mathrm{MoS}_{2}$ sputtered films produced a nanocomposite structure, increasing the hardness and reducing the wear. Similar works were also reported by Nossaet. al. [39].

Until now, most of the studies on the TMD-N (in particular Mo-S-N) systems were performed for a stationary substrate holder placed in front of the target; the effect of rotating the substrate holder for industrial purpose is still unexplored. Also, as per literature, the desired amorphous phase was achieved at the cost of a high nitrogen doping and consequent sub-stoichiometry of the TMDs. Therefore, further studies are required to overcome chalcogen atom depletion with nitrogen additions. Another important shortcoming in TMD-N coatings is the lack of adhesion to the substrates, even after the use of metallic interlayers. All previous works report the use of $\mathrm{Ti}$ or $\mathrm{Cr}$ interlayers for adhesion improvement [40-42], with Ti being a more suitable option [20]. Nonetheless, Nossa et. al. [43] showed that spalling occurred between the films and $\mathrm{Ti}$ interlayer during the scratch test, preventing the substrate exposure. Besides, TiN was also used as interlayer which resulted in an improved adhesion over Ti, due to a good interface bonding between TiN and Mo-S-N coatings [41]. 
However, the drawback is the associated cost increments due to the use of an additional Ti target sputtering.

This study is aimed to counter all these issues for TMD-N coatings by depositing those using DCMS. To our knowledge, this is the first time that DC magnetron sputtering has been used for depositing Mo-S-N coatings. Here, only one $\mathrm{MoS}_{2}$ target was used to decrease the operating costs. An alternative to traditional metallic interlayers for enhancing the adhesion was the use of a novel N-doped metal-rich Mo-S-N layer, instead of Ti or Cr, avoiding the use of a second cathode. An additional plasma source was used to adjust the ion to neutral ratio during film growth, providing control over the coating morphology and S/Mo ratio. The achievement of a good coating integrity, as well as a high S/Mo ratio, is sought in order to make coatings capable of providing enhanced sliding performances. The deposition was followed by a detailed characterization of the coatings with respect to composition, morphology, structure and chemical bonding.

\section{EXPERIMENTAL DETAILS}

Mo-S-N films were deposited on polished Si (100) wafers and polished M2 steel (Ø25 mm x $6 \mathrm{~mm}$, hardness of $62 \mathrm{HRC}$ ) substrates in a balanced DC magnetron sputtering configuration, using a custom-built TSD 400 semi-industrial plasma vapour deposition machine. The chamber was equipped with a single cathode and an additional independent plasma source, facing the substrate. The additional secondary plasma source serves the following function; (i) it creates a low argon pressure plasma which is used to etch the steel substrates, (ii) during the coating process, it is used to vary the ion to neutral ratio coming to the substrates, (iii) the plasma density or current density can be tuned at the substrate by adjusting the plasma source power. For the current process, the plasma source power was kept constant for all the deposition steps. Sintered molybdenum disulphide $\mathrm{MoS}_{2} 450$ $\mathrm{mm} \times 150 \mathrm{~mm} \times 5 \mathrm{~mm}(99.5 \%$ purity) target was sputtered in $\mathrm{N}$ and $\operatorname{Ar}(99.99 \%$ purity) gas atmosphere. The substrates were placed over a planetary (double rotation) substrate holder rotating at a speed of $5 \mathrm{rpm}$. Prior to deposition, the chamber and substrates were heated to $150{ }^{\circ} \mathrm{C}$ for 5 hours with consequent pumping to the base pressure of $\sim 10^{-4} \mathrm{~Pa}$, to remove any moisture and adsorbed 
contaminants. The top view schematic diagram of the deposition chamber is shown in figure 1.

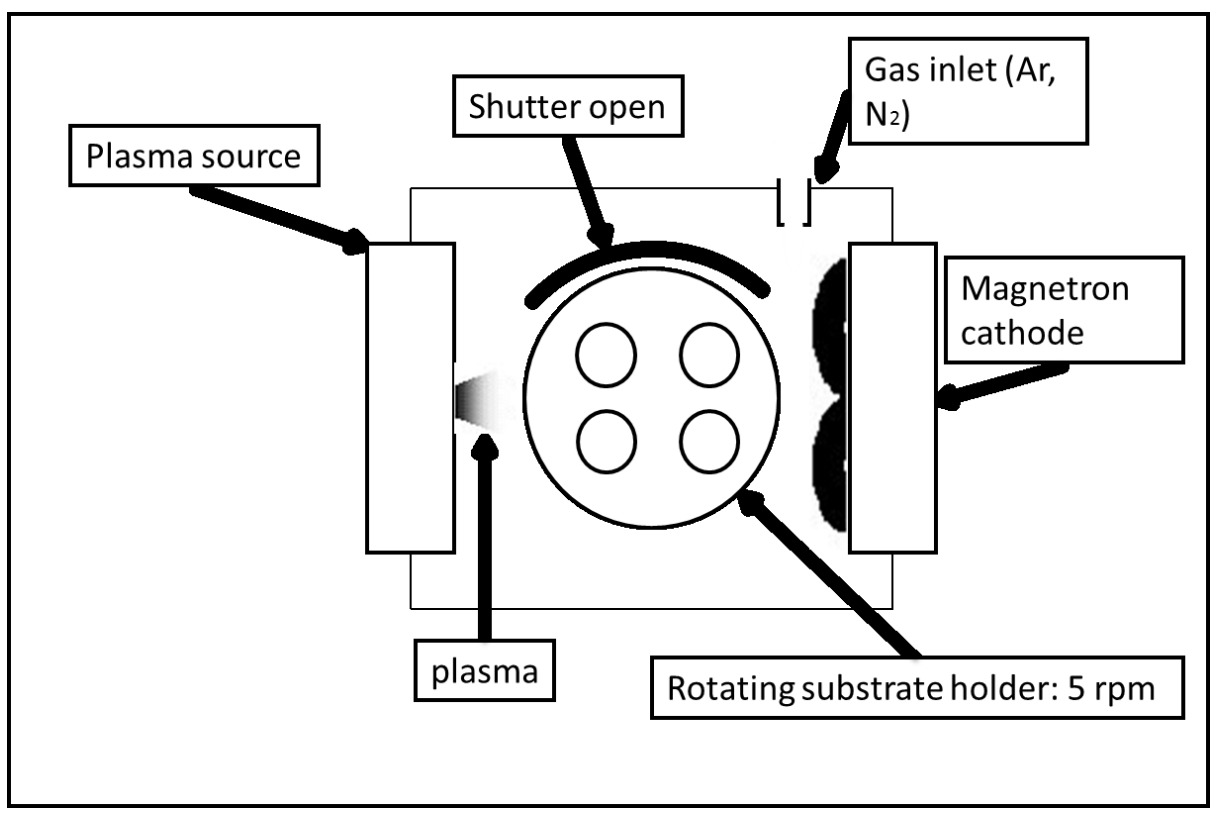

Figure 1: Schematic setup of the TSD 400 PVD chamber (Top view).

Substrate etching was performed with $\mathrm{Ar}^{+}$ions bombardment by applying $-150 \mathrm{~V}$ at $0.3 \mathrm{~Pa}$ using the additional plasma source, for 60 minutes, while the target was sputteredcleaned for 7 minutes by applying $1000 \mathrm{~W}$ DC power. The first step in the coating recipe was the deposition of 'novel gradient layers', which took 20 minutes. Here, the Mo rich layer was deposited by intense ion bombardment of the growing film with $\mathrm{Ar}^{+}$ions resulting in preferential resputtering of $\mathrm{S}$ atoms. This was done to obtain good metal-metal bonding with the steel substrate followed by the introduction of nitrogen in the presence of high ion energy and ion bombardment from the additional plasma source, to achieve nitrides containing sulphur. Then, progressively, the ion energy was decreased to incorporate more sulphur. After 20 minutes, the final coating was deposited in such a way that nitrogen would be already present within the coatings and plasma trying to prevent lamellar $\mathrm{MoS}_{2}$ formation During the deposition of Mo-S-N films, the Ar gas flow was kept constant at $70 \mathrm{sccm}$ whereas the $\mathrm{N}_{2}$ gas flow was varied between 0-60 sccm (Table-1) to achieve different $\mathrm{N}$ content in the coatings; the process pressure ranged from 0.45 to $0.70 \mathrm{~Pa}$. The rotating substrates underwent alternating exposure to the cathode (target) and ion bombardment from the additional 
secondary plasma source. The coatings were deposited at $1000 \mathrm{~W}$ DC power applied to the target. A negative pulsed DC substrate bias of $50 \mathrm{~V}$ was applied during the deposition to enhance the compactness. The pulse conditions were set at $250 \mathrm{kHz}$ of frequency, $950 \mathrm{~ns}$ of duration ( $76.25 \%$ duty cycle). The target to substrate distance was $100 \mathrm{~mm}$. The total deposition time was 2 hours in the $\mathrm{N}_{2}$ reactive atmosphere. This deposition time was selected to yield a final coating thickness of 1.2-3 microns as shown in figure 2.

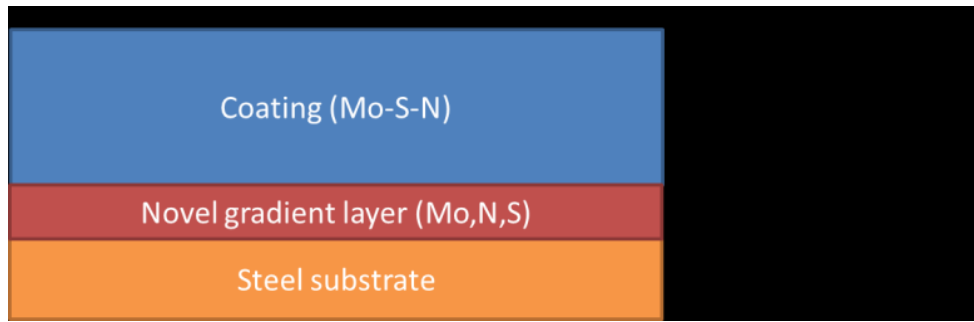

Figure 2: Schematic representation of the layer structure and thickness.

Coating's integrity or adhesion on the M2 steel substrates (Ø25 $\mathrm{mm} \times 6 \mathrm{~mm}$ ) was evaluated by scratch-testing (CSM Revetest). The specimens were scratched as the normal force was progressively increased from 5 to $80 \mathrm{~N}$, using a Rockwell indenter (tip radius $=0.2 \mathrm{~mm}$ ) at a scratch speed of $10 \mathrm{~mm} / \mathrm{min}$ and a loading rate of $100 \mathrm{~N} / \mathrm{min}$. Three tests were done on each sample to confirm the critical load. Later, the critical adhesion loads were determined by analysing scratches by optical and scanning electron microscopies, based on the report of Camino et al. [44]. The chemical composition of the coatings was determined by wavelength dispersive spectroscopy, WDS (Oxford Instruments).

Spectroscopic studies of plasma-chemistry and element specific plasma imaging were performed to study the re-sputtering effect of Sulphur from the substrate. A quartz window (transmittance cut-off $\sim 180 \mathrm{~nm}$ ) was arranged with a view parallel to the substrate surface and perpendicular to the substrate-plasma source (i.e. magnetron and secondary plasma source) axis, capturing light emitted from the plasma region between the plasma source and the substrate location. For spectral line recording, the fibre optic spectrometer (AVS-S2000) accepts light energy transmitted through single-strand optical fibre and disperses it via a fixed grating across the linear CCD array detector. 
The obtained spectral intensities versus wavelengths are processed using SpectraWIN BASIC 5.0 software. The monochromator provides $\sim 0.1 \mathrm{~nm}$ resolution of spectral bands collected over a 300-1000 $\mathrm{nm}$ range. The peak intensity corresponding to the wavelength of $550 \mathrm{~nm}$ is considered for Sulphur and $811 \mathrm{~nm}$ for argon which corresponds to the single ionized states of each element.

X-ray photoelectron spectroscopy (XPS) was used for chemical bonding analysis. The samples were analysed in a KratosAxis Ultra HAS equipment with monochromatic Al $\mathrm{K} \alpha \mathrm{X}$-beams $(\mathrm{h} v=1486.6 \mathrm{eV})$. The power of the X-beam source was set to $90 \mathrm{~W}$ and a charge neutralizer was utilized during estimations. The survey spectra were gotten by setting the pass energy at $80 \mathrm{eV}$ with a step of $1 \mathrm{eV}$ and a dwell time of $200 \mathrm{~ms}$. The high-resolution spectra of the regions of interest were acquired utilizing a pass energy of $40 \mathrm{eV}$ with a step of $0.1 \mathrm{eV}$ and a dwell time of $600 \mathrm{~ms}$. Sputter etching was performed utilizing Ar+ ion gun operated at $2.2 \mathrm{keV}$ and current density of $2.2 \mu \mathrm{A} / \mathrm{cm} 2$. The data collection and analysis were done at pressures lower than $10^{-6} \mathrm{~Pa}$. The data was investigated utilizing the CasaXPS software. The baselines of the spectra were obtained utilizing the Shirley strategy and pinnacle fitting was finished utilizing GaussianLorentzian functions. The surface morphologies, fractured cross-section morphologies and the thickness of the coatings were checked by field emission scanning electron microscopy-SEM (Zeiss Merlin). Grazing incidence $\left(3^{\circ}\right)$ X-ray diffraction (XRD) measurements were performed using an X-Pert Pro MPD diffractometer with $\mathrm{Cu} \mathrm{K}_{\alpha 1}$ $(\lambda=1.54 \AA)$ radiation source.

The microstructural and high-resolution (HR) TEM imaging was performed using a probe corrected Jeol ARM 200F electron microscope operating in STEM mode at 200 $\mathrm{kV}$ acceleration voltage and an image corrected FEI Titan ${ }^{3}$ operating in TEM mode at $300 \mathrm{kV}$ acceleration voltage. The lamellae were prepared by focused ion beam (FIB) using a FEI Helios Nanolab electron microscope.

\section{RESULTS}

\subsection{Coating integrity}

The innovative single target deposition coupled with additional secondary plasma source offered a remarkable improvement of adhesive strength and coating's integrity 
without the use of a third element metallic interlayer (such as $\mathrm{Ti}$ or $\mathrm{Cr}$ ). The effect of coating architecture (novel gradient layer) on scratch resistance behaviour of pure $\mathrm{MoS}_{2}$ coating and selected Mo-S-N coating has been shown in Table 1. The coatings deposited without the novel gradient layer had a substantially low adhesive failure limit while the introduction of the novel gradient layer in the coatings enhanced the adhesion failure resistance beyond the tested range. No evidence of delamination or penetration through the steel was observed. So, this enhancement is solely related to the strong adherence achieved by metal-metal bonding, induced by the deposition procedure.

Table 1: Table representing the cohesive failure limit and adhesive failure limit for pure $\mathrm{MoS}_{2}$ and $\mathrm{Mo}-\mathrm{S}$ $N$ coatings made with and without a novel gradient layer. The adhesive failure limit is beyond the tested load.

\begin{tabular}{ccc}
\hline $\begin{array}{c}\text { Sample } \\
\text { Pure } \mathrm{MoS}_{2} \text { coating }\end{array}$ & $\begin{array}{c}\text { Cohesive failure limit } \\
(\text { Lc1) }\end{array}$ & $\begin{array}{c}\text { Adhesive failure limit } \\
\text { without novel gradient layer }\end{array}$ \\
$\begin{array}{c}\text { Pure MoS coating with } \\
\text { novel gradient layer }\end{array}$ & $3.9 \mathrm{~N}$ & \\
\hline Mo-S-N coating & & $>80 \mathrm{~N}$ \\
\hline without novel gradient layer \\
Mo-S-N coating with \\
novel gradient layer
\end{tabular}



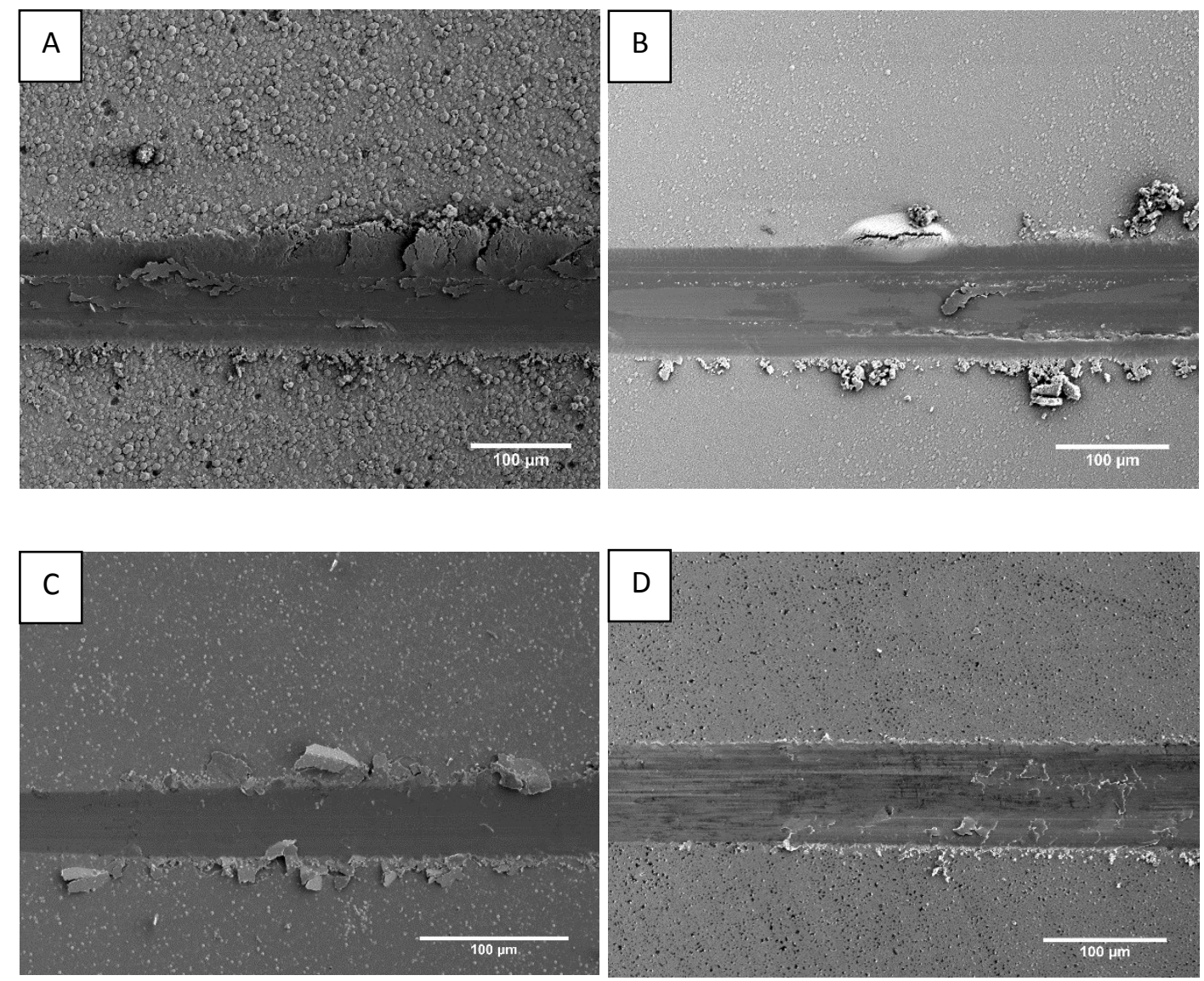

Figure 3:- SEM images of cohesive failures of materials with pure $\mathrm{MoS}_{2}$ and Mo-S-N with and without novel gradient layer. (A) Pure $\mathrm{MoS}_{2}$ coating without a novel gradient layer. (B) Pure $M o S_{2}$ with novel gradient layer. (C) Mo-S-N coating without novel gradient layer. (D) Mo-S-N coating with novel gradient layer.

The scratch test tracks were analysed in SEM and are shown in figure 3. It was again observed that the novel gradient layer improved the scratch resistance of the coating. Large flakes were observed as a result of cohesive cracking in the films deposited without the novel gradient layer. Similarly, nitrogen doping further enhanced the adhesion and scratch resistance. This improvement for nitrogen-doped coatings, as compared to the pure coatings, is attributed to the formation of dense structures that prevents delamination or exfoliation of lamella within the coatings, thus increased the load-bearing capacity. 


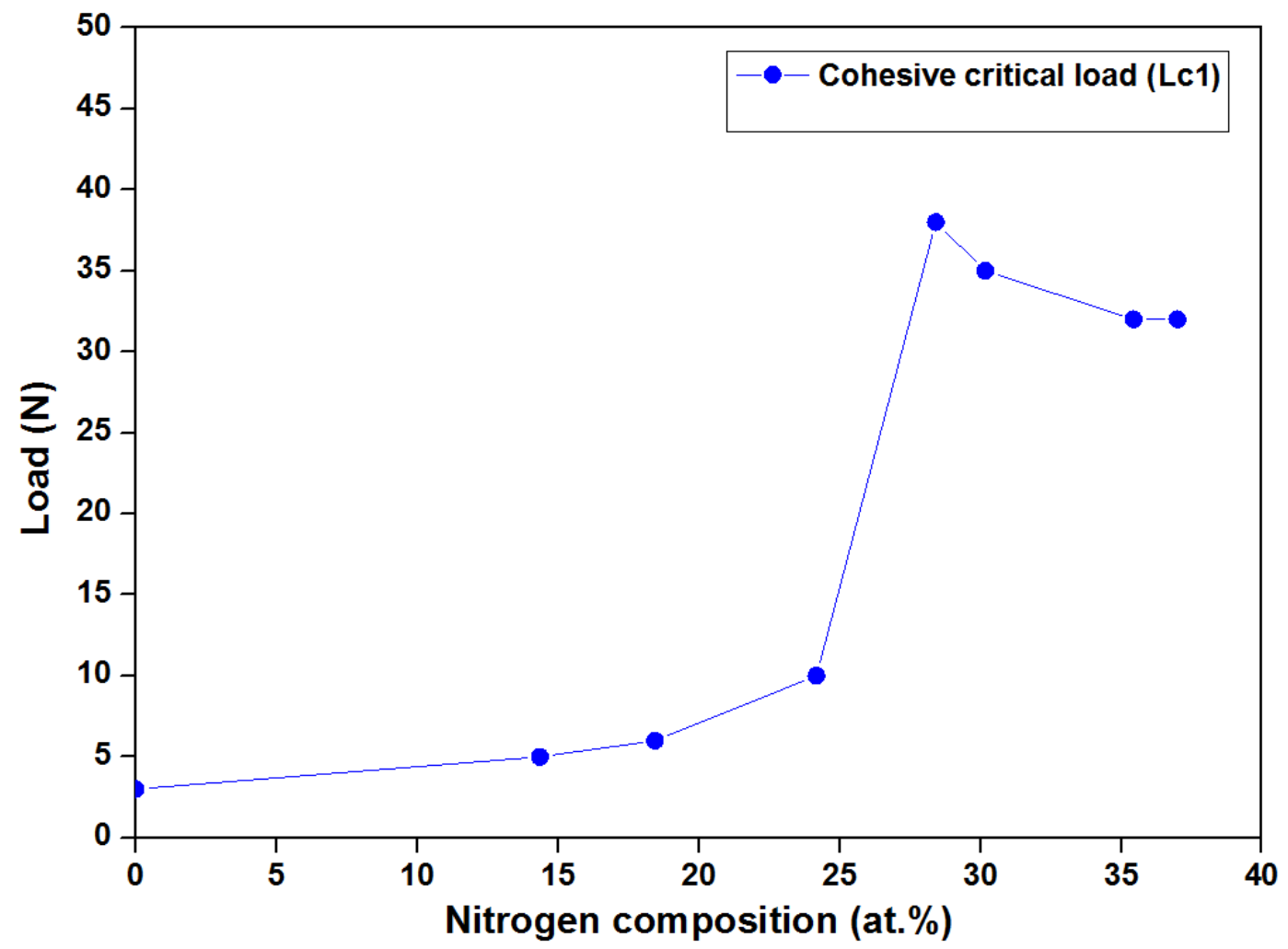

Figure 4: Evolution of scratch behaviour Lc1 (cohesive critical load or cohesive failure limit) for pure $\mathrm{MoS}_{2}$ and Mo-S-N films with respect to the nitrogen compositions.

Figure 4 shows the effects of nitrogen content on the initial load required for cohesive failure $\left(\mathrm{L}_{\mathrm{c} 1}\right)$. As soon as the nitrogen was introduced to the $\mathrm{MoS}_{2}$ coatings, there was improvement in the critical load for cohesive failure as said above. In general, the increase in nitrogen content increased the failure limit or late appearance of flakes in the scratch test. The increase was almost linearly until 24 at. $\%$ of nitrogen incorporation but, after this, a sudden increase in scratch resistance was observed. This sudden increase could be due to enhanced amorphousness (or nanocomposite structure) of the coatings, which eliminates the presence of any laminar crystals, thus avoiding cohesive failures. So, as expected, the nitrogen content and the novel gradient layers have played a major role in the enhancement of the cohesive failure resistance and provided a good adhesion of these coatings to the substrate without the need of any other metallic interlayer (or the use of a second target).

In order to investigate in depth the mechanisms behind this high stability and the scratch resistance of the deposited coatings, cross-sectional analysis was performed for one of the nitrogen-doped films deposited with the novel gradient layer. 
Figure 5 shows HR-TEM images at the substrate interface. A $10 \mathrm{~nm}$ thick Mo film followed by an ultrathin multilayer system with a periodicity of $5 \mathrm{~nm}$ was observed. The structural analysis showed that the first Mo layer forms the base for the growth of a nanocomposite MoN multilayer. The layer structure formation is caused by the planetary motion of the substrate holder and the alternative exposure to the magnetron cathode and the plasma source providing mainly argon and nitrogen ions, respectively.
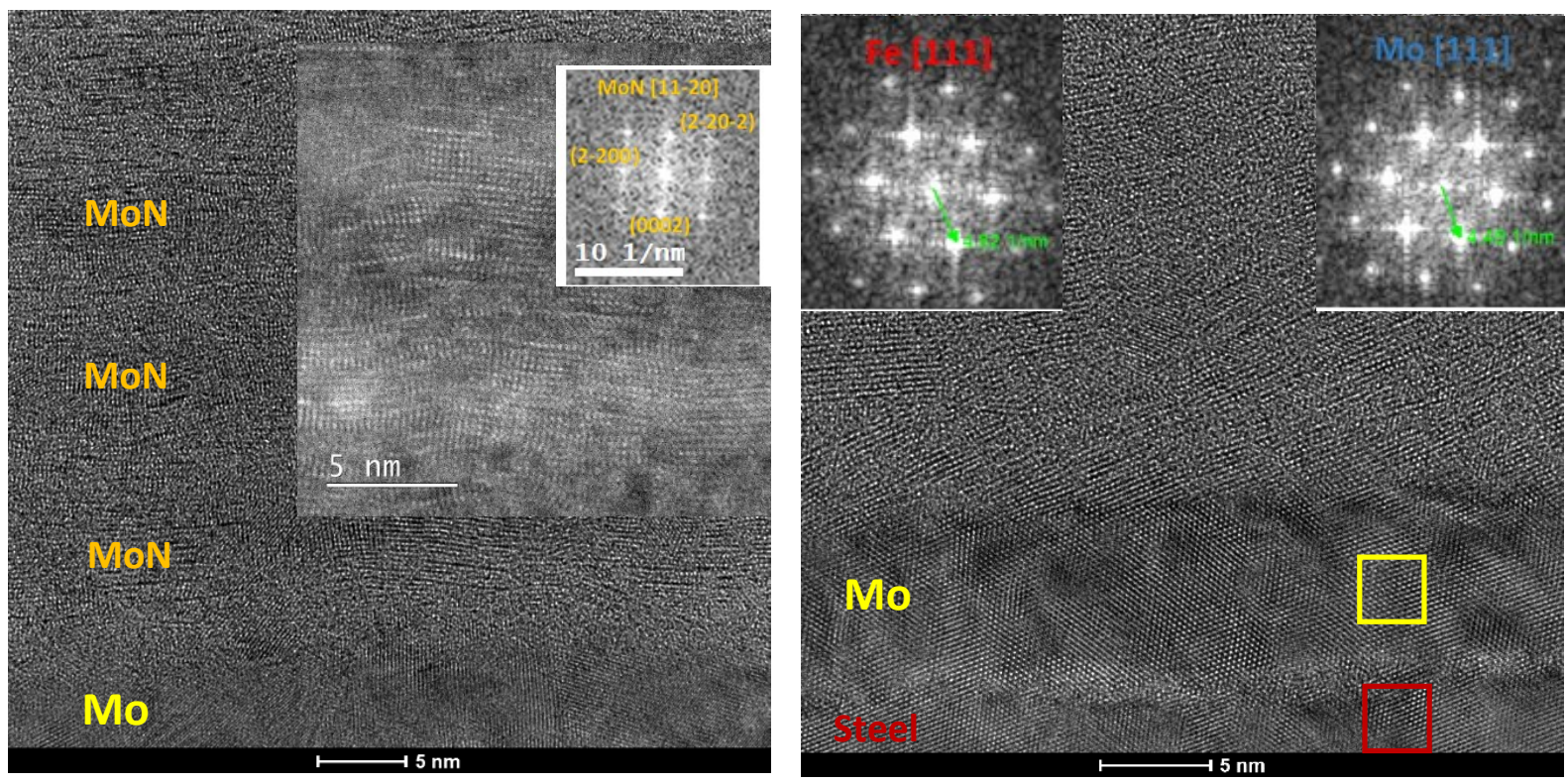

Figure 5: (Left) Microstructure of novel gradient layers from an as-deposited coating cross-section. (Right) The first layer Mo over steel making metal-metal bonding with Fe; delivers improved adhesion. Preferential resputtering of sulphur had caused this layer to be sub-stoichiometry (S/Mo=approx. 0.3).

Epitaxial stacking between $\mathrm{Fe}$ and Mo was observed along the substrate interface, as a result of a small lattice mismatch (7.3\%) between the two unit cells, causing defect-free coherent crystal growth in large areas of the substrate. The first Mo layer becomes the seed for the formation of a laminar MoN composite. The hexagonal MoN provides increased hardness, shear strength and superior adhesion of the film. Nitrides are formed by selectively removing sulphur through surface resputtering by exposing the substrate to high ion energy (substrate bias) and nitrogen ion bombardment (secondary plasma source). As shown in figure 6, the growth direction of Mo followed by the MoN-rich composition gradient layer ( $\mathrm{S}$ deficient) is dependent on the orientation of the neighbouring substrate grains; therefore, the novel gradient layer 
changes the crystalline direction depending on the substrate interface orientation. In order for the Mo bonding layer to withstand the increased mechanical strain and allow for plastic deformation without brittle failure under increased loads, coherent interfaces are required. Figure 6 show examples of such atomic arrangements which occur as a result of the matching crystal structures of Fe, Mo and MoN.
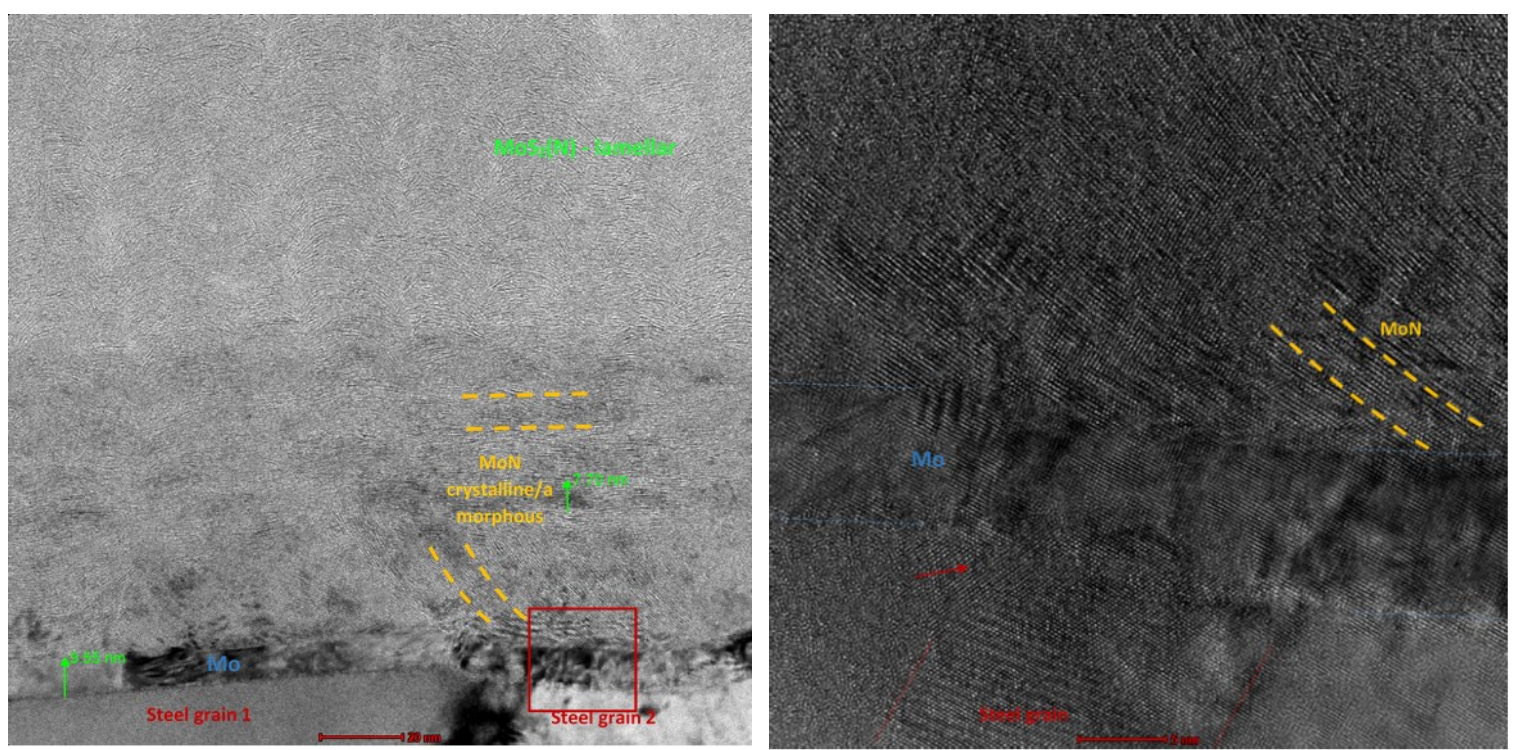

Figure 6: (Left) Morphology of the Mo/MoN(S) novel gradient layer. (Right) Epitaxial deposition of Mo and MoN on steel substrate; strong substrate interface.

\subsection{Chemical Composition and Deposition Rate}

The chemical composition of pure $\mathrm{MoS}_{2}$ and all the Mo-S-N coatings with increasing nitrogen composition/content were analysed by wavelength dispersive spectroscopy (WDS) as shown in table 2. It was observed that even for the pure $\mathrm{MoS}_{2}$ coatings $(0$ at. $\% \mathrm{~N})$, the $\mathrm{S} / \mathrm{Mo}$ ratio was less than $\mathrm{MoS}_{2}$ stoichiometric composition $(\mathrm{S} / \mathrm{Mo} \sim 2)$. 
Table 2: The chemical composition of all Mo-S-N coatings. The number suffix of sample code indicates the nitrogen flow used for a particular test.

\begin{tabular}{|c|c|c|c|c|c|c|c|}
\hline Sample & $\begin{array}{c}\mathbf{N}_{\mathbf{2}} \text { flow } \\
\text { (sccm) }\end{array}$ & Mo (at. \%) & S (at. \%) & N (at. \%) & S/Mo & $\begin{array}{c}\text { Thickness } \\
(\mu \mathbf{m})\end{array}$ & $\begin{array}{c}\text { Deposition } \\
\text { rate (nm/min) }\end{array}$ \\
\hline MoS $2(N 0)^{(N 0}$ & 0 & $35.4 \pm 0.4$ & $63.4 \pm 0.5$ & 0 & 1.79 & 6.1 & 51.3 \\
\hline MoSN10 $_{\text {MoSN20 }}$ & 20 & $30.8 \pm 0.3$ & $48.5 \pm 0.3$ & $18.4 \pm 0.8$ & 1.57 & 2.4 & 20.0 \\
MoSN30 & 30 & $30.5 \pm 0.4$ & $43.2 \pm 0.4$ & $24.2 \pm 0.7$ & 1.42 & 2.2 & 18.5 \\
MoSN40 & 40 & $29.0 \pm 0.4$ & $40.3 \pm 0.3$ & $28.4 \pm 0.8$ & 1.33 & 1.5 & 12.9 \\
MoSN50 & 50 & $27.9 \pm 0.4$ & $34.8 \pm 0.4$ & $35.4 \pm 0.7$ & 1.26 & 1.2 & 11.5 \\
MoSN60 & 60 & $27.3 \pm 0.4$ & $34.1 \pm 0.4$ & $37.0 \pm 0.8$ & 1.25 & 1.2 & 10.5 \\
\hline
\end{tabular}

Several physical mechanisms can be involved for sulphur depletion, like resputtering by fast reflected neutrals $[43,45]$, resputtering by the ion bombardment [46] or even self-desorption of sulphur from the coating surface [47]. Figure 7 represents some evidence of preferential resputtering of sulphur studied using optical spectroscopy, by collecting the light emissions of the plasma at secondary plasma source and target. From $0 \mathrm{~V}$ to $100 \mathrm{~V}$, no significant increase in the ratio of intensities of sulphur to argon was observed in both cases (between target and substrate, and between secondary plasma source and substrate). This could indicate that the resputtering effect, due to the ion energy, is absent $(0 \mathrm{~V}$ to $100 \mathrm{~V})$. On the other hand, beyond $100 \mathrm{~V}$, an increase in the emission intensities occurs, showing that the resputtering of $\mathrm{S}$ from the film becomes intense (as seen between secondary plasma source and substrate). Similar behaviour was also observed elsewhere [42]. So, such low or almost negligible resputtering at $50 \mathrm{~V}$ leads to the conclusion that the substoichiometry of $\mathrm{MoS}_{2}(\mathrm{~N} 0)$ can be better attributed to desorption of sulphur. 


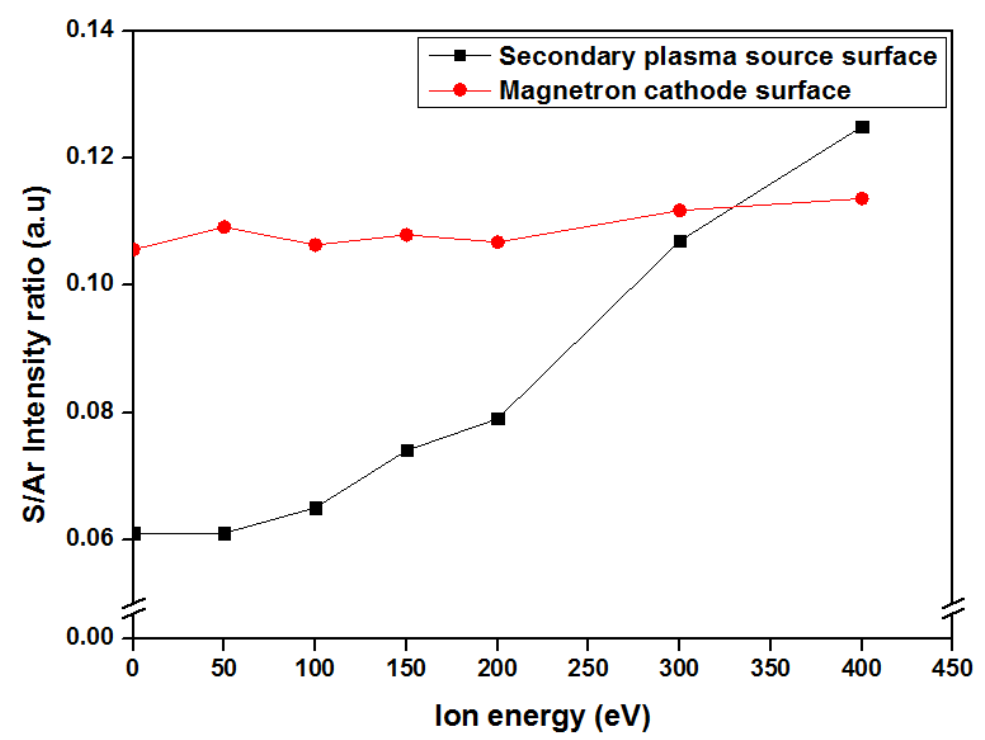

Figure 7: Effect of resputtering of sulphur can be observed by optical emission of sulphur atom at $550 \mathrm{~nm}$ wavelength with respect to ion energy $(\mathrm{eV})$ or substrate bias voltage. The intensity is normalised with $\mathrm{Ar}$ intensity for consistency. The tests were done with cathode power of $1000 \mathrm{~W}$.

The substrate bias is known to increase the compactness of coatings through the re-deposition of atoms in less dense areas. The acceleration voltage also increases adatom mobility $[21,48]$. The measured S/Mo ratio for pure coating was 1.8 which is a higher value when compared to other reported results for pure $\mathrm{MoS}_{2}$ films (S/Mo-1.6) $[31,49]$. This result is tentatively attributed to a highly degassed chamber due to a long heating and pumping prior to deposition. This procedure minimizes the presence of residual gases, like $\mathrm{H}_{2} \mathrm{O}$, which could react to sulphur atoms and, then, decreasing the $\mathrm{S}$ content of this element in the film. This was further evidenced by a comparative experiment performed with just 1 hour of degassing, for which an evident strong smell was detected $\left(\mathrm{H}_{2} \mathrm{~S}\right.$ or $\left.\mathrm{SO}_{\mathrm{x}}\right)$ indicating the sulphur reacts with the residual gas. For the usual 5 hours of heating prior to deposition, no smell was detected when the opening the chamber after the coating deposition, meaning that the chamber is almost free of contamination gases (mainly $\mathrm{H}_{2} \mathrm{O}$ ). On the other hand, the oxygen concentration in the $\mathrm{N}$-doped and pure $\mathrm{MoS}_{2}$ coatings was low at $0.5-1.5$ at. $\%$ and up to 4 at. $\%$ respectively; a factor of $\sim 2$ lower as when compared to values reported in the literature [49]. 


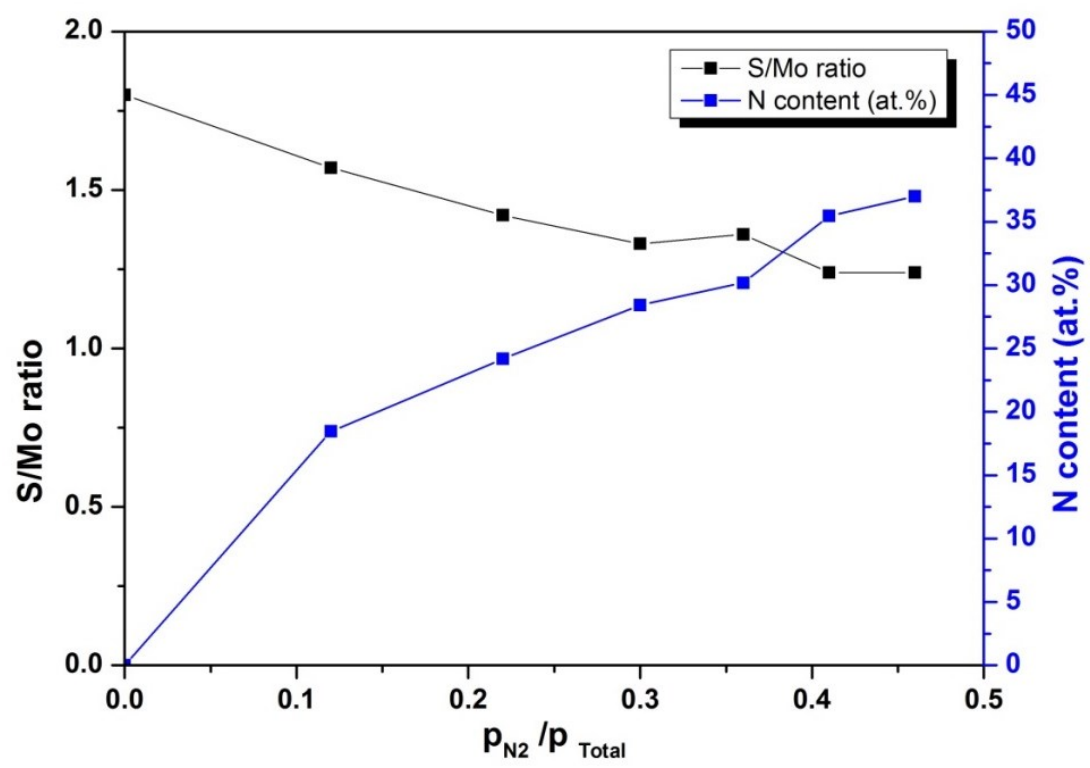

Figure 8: Evolution of S/Mo ratio and $N$ content in the films as a function of the partial pressure of nitrogen gas.

The increase in the nitrogen flow rate during the deposition and the effect on the composition of the coating are shown in Table 2 and Figure 8. The Mo content remained nearly unchanged whereas the sulphur content gradually decreased, suggesting that nitrogen is replacing sulphur in the Mo-S compound. Overall, the minimum value for $\mathrm{S} / \mathrm{Mo}$ was 1.25 and the $(\mathrm{S}+\mathrm{N}) /$ Mo ratio was in the range of 2.172.50. These values higher than 2 also shows that nitrogen molecules can be trapped between the lamellas of $\mathrm{MoS}_{2}$ as it was reported by Isaeva et. al. [36]. $\mathrm{N}$ can also be located at interstitial positions in the $\operatorname{MoS}\left(\mathrm{N}_{2}\right)$ compound which causes the formation of an amorphous structure. 
Table 3: Chemical composition of Mo-S-N films with and without the use of secondary plasma source for Mo-S-N films with $30 \mathrm{sccm} \mathrm{N}_{2}$ flow.

\begin{tabular}{|c|c|c|c|c|c|c|}
\hline Sample & Mo (at. \%) & S (at. \%) & $\begin{array}{l}\text { N (at. } \\
\% \text { ) }\end{array}$ & $\begin{array}{c}\text { O (at. } \\
\% \text { ) }\end{array}$ & S/Mo & $\begin{array}{c}\text { Deposition rate } \\
\text { (nm/min) }\end{array}$ \\
\hline $\begin{array}{l}\text { With secondary } \\
\text { plasma source }\end{array}$ & $30.2 \pm 0.3$ & $40.3 \pm 0.3$ & $28.4 \pm 0.8$ & $1.1 \pm 0.2$ & 1.33 & 12.9 \\
\hline $\begin{array}{c}\text { Without secondary } \\
\text { plasma source }\end{array}$ & $30.7 \pm 0.3$ & $48.4 \pm 0.4$ & $18.0 \pm 0.4$ & $2.9 \pm 0.2$ & 1.57 & 15.8 \\
\hline
\end{tabular}

To understand the influence of the ion bombardment, one of the coatings (Mo-S$\mathrm{N}$ with $30 \mathrm{sccm}$ flow) was deposited without the use of additional secondary plasma source (keeping the other parameters constant) and the results are shown in Table 3 . The film without the use of additional secondary plasma source had only 18 at. \% of nitrogen content and S/Mo ratio of 1.57 against the 28 at. \% and 1.33, respectively, for MoSN30 (30 sccm nitrogen flow); the $\mathrm{O}$ content also was higher. This evolution is in agreement with the above described influence of the bombardment on the film growth promoting the resputtering of lighter elements from the growing film and its densification. The bombardment with nitrogen ions can facilitate their sub-plantation in the film and the replacement of the re-sputtered sulphur atoms.

Table 2 shows that $\mathrm{MoS}_{2}(\mathrm{~N} 0)$ coating has the highest deposition rate as compared to Mo-S-N coatings. The reported deposition rates correspond to the coatings without considering the growth of the novel gradient layer. Several factors can contribute to this trend as follows:

(i) With the introduction of nitrogen in the chamber, $\mathrm{N}_{2}$ is mixed with Ar in the plasma, decreasing the sputtering efficiency, leading to a reduction of Mo and S sputtering yields [50].

(ii) Nitrogen is being ionized by the secondary plasma source, with the consequent increasing bombardment of the growing film. Therefore, the densification of film occurs. The bombardment and incorporation of $\mathrm{N}$ led to atomic arrangements and the removal of pores and voids, as it has been reported in the literature [49]. The 
compaction decreases the film thickness for the same amount of deposited material with the consequent decrease in the deposition rate.

(iii) The ion bombardment of the growing film induces the resputtering of the incoming species, decreasing the amount of deposited atoms and the deposition rate.

\subsection{Chemical Bonding}

The ion bombardment of the growing film induces the resputtering of the incoming species, decreasing the amount of deposited atoms and the deposition rate. The character of the chemical bonding between the atoms forming Mo-S-N films was studied by XPS and the peak positions were identified using the NIST database[51]. The representative XPS Mo3d, S2p, N1s and Mo3p $\mathrm{p}_{3 / 2}$ core level spectra of N 0 at.\% (0 sccm), N 18 at.\% (10 sccm), N 28 at.\% (30 sccm) and N 35 at.\% (50 sccm) are shown in figure 9. The XPS spectra have been fitted by Gaussian-Lorentzian curves. The relative contents of the various valence states are estimated from the integral area under the Gaussian curves. The Mo3d spectrum is fitted to the doublet peaks at $229.0 \mathrm{eV}$ and $232.4 \mathrm{eV}$ [46], corresponding to MoN bonds with approx. $3.4 \mathrm{eV}$ spin-orbit splitting; the $228.3 \mathrm{eV}$ and $231.5 \mathrm{eV}$ peaks with $3.2 \mathrm{eV}$ spin-orbit splitting are corresponding to the chemical bonds between Mo and S typical for $\mathrm{MoS}_{2}$, and the doublet peaks at 230.0 $\mathrm{eV}$ and $233.3 \mathrm{eV}$ belongs to Mo-O with $3.3 \mathrm{eV}$ splitting. It can be seen that the MoS2 contribution is still dominant in the Mo3d spectrum. The Mo-O bond is almost vanished indicating that there was no oxidation in the film bulk. The peak at $226.3 \mathrm{eV}$ belongs to $\mathrm{S} 2 \mathrm{~s}$. The S2p spectrum at $162.0 \mathrm{eV}$ becomes slightly broader and lower intensity from 18 at. $\%(10 \mathrm{sccm})$ to 35 at. $\%(50 \mathrm{sccm})$ due to loss of $\mathrm{S}$ element in the film. The N1s spectrum partially overlaps with Mo3 $\mathrm{p}_{3 / 2}$ peaks, which is in good agreement with the reported in the literature $[31,49]$. With the increase of $\mathrm{N}$ content, the intensity of the N1s signal increases. The binding energy of N1s displays a main contribution at $397.5 \mathrm{eV}$, corresponding to N-Mo bonds. N1s XPS peaks are important to understand the Mo-S-N compound films because the N-Mo bond peaks increases with the incorporation of nitrogen into the coatings and similar results were also observed in other experiments $[52,53]$. From our measurements, we can conclude that, with the increase of $\mathrm{N}$ content from 0 at. $\%(0 \mathrm{sccm})$ to 35 at. $\%(50 \mathrm{sccm})$, the relative amount of Mo-N seems to increase. Still, there is much more Mo-S present as evident from the intensity of S2s 
peaks at $226.3 \mathrm{eV}$ and also the presence of Mo-S peaks. This is achieved through the periodic exposure to $\mathrm{N}$-rich ion bombardment and $\mathrm{MoS}_{2}$ target during the rotation of the substrate holder.
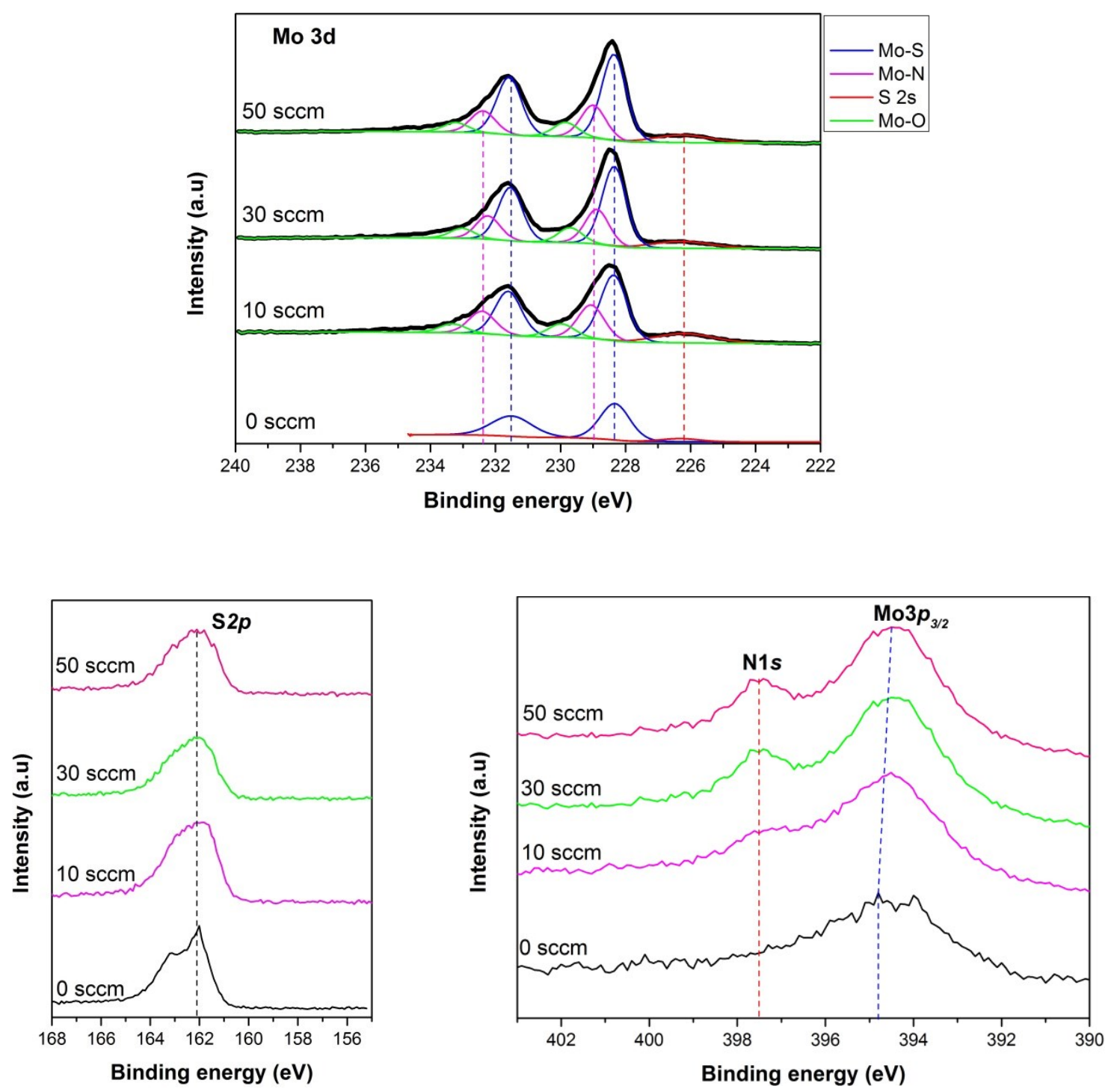

Figure 9: XPS spectra from Mo3d, S2p and N1s-Mo3p 3/2 from the Mo-S-N films deposited at 18 at. \% N $(10 \mathrm{sccm}), 28$ at. $\% \mathrm{~N}(30 \mathrm{sccm})$ and $35 \mathrm{at} . \% \mathrm{~N}(50 \mathrm{sccm})$ respectively. $0 \mathrm{sccm}$ refers to pure $\mathrm{MoS}_{2}$ spectra.

\subsection{Fractured Cross-section and Surface Morphology}

Figure 10 shows the fractured cross-section and surface morphologies of the deposited coatings. The sputtered pure $\mathrm{MoS}_{2}$ coating displayed highly porous and low density cross-section morphology with a large contribution of dendritic growth throughout the coating (Figure $10 a$ ). Surface morphology of this coating was in 
accordance with the cross-sectional results and the evidences of dendritic growth were clearly visible (Figure $10 \mathrm{~b}$ ). For Mo-S-N coatings, even with the introduction of the lowest amount of nitrogen (18 at. \%), the coatings started to become compact and displayed columnar morphology (Figure $10 c$ ). The surface morphology micrograph for this coating also displayed less porous and sponge-like morphology (Figure $10 d$ ). With further nitrogen incorporations, the compactness and density continued to increase, while the surface displayed cauliflower like morphology due to surface limited diffusion conditions $[3,54]$. A significant increase in the compactness was observed after 28 at. $\%$ $\mathrm{N}$ addition.

The thickness of the coatings displayed trends similar to compactness with the highest thickness of the $\mathrm{MoS}_{2}$ coating $(6.1 \mu \mathrm{m})$ decreasing with increasing the nitrogen content (as low as $1.2 \mu \mathrm{m}$ ). Despite more atoms being added as compared to the pure coating, the substantial thickness decreases are being attributed to the removal of porosity and increase of the density and compactness. 

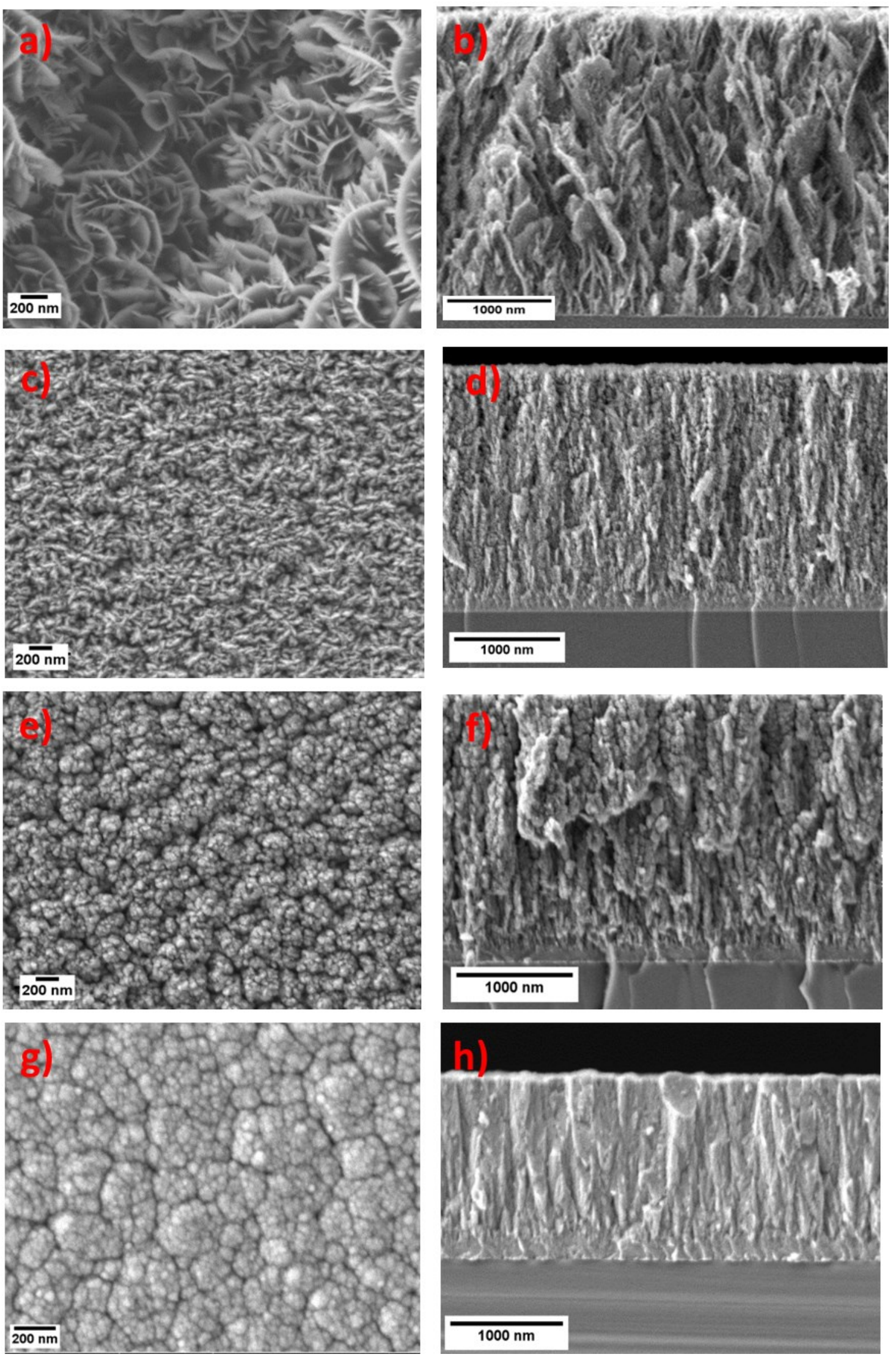

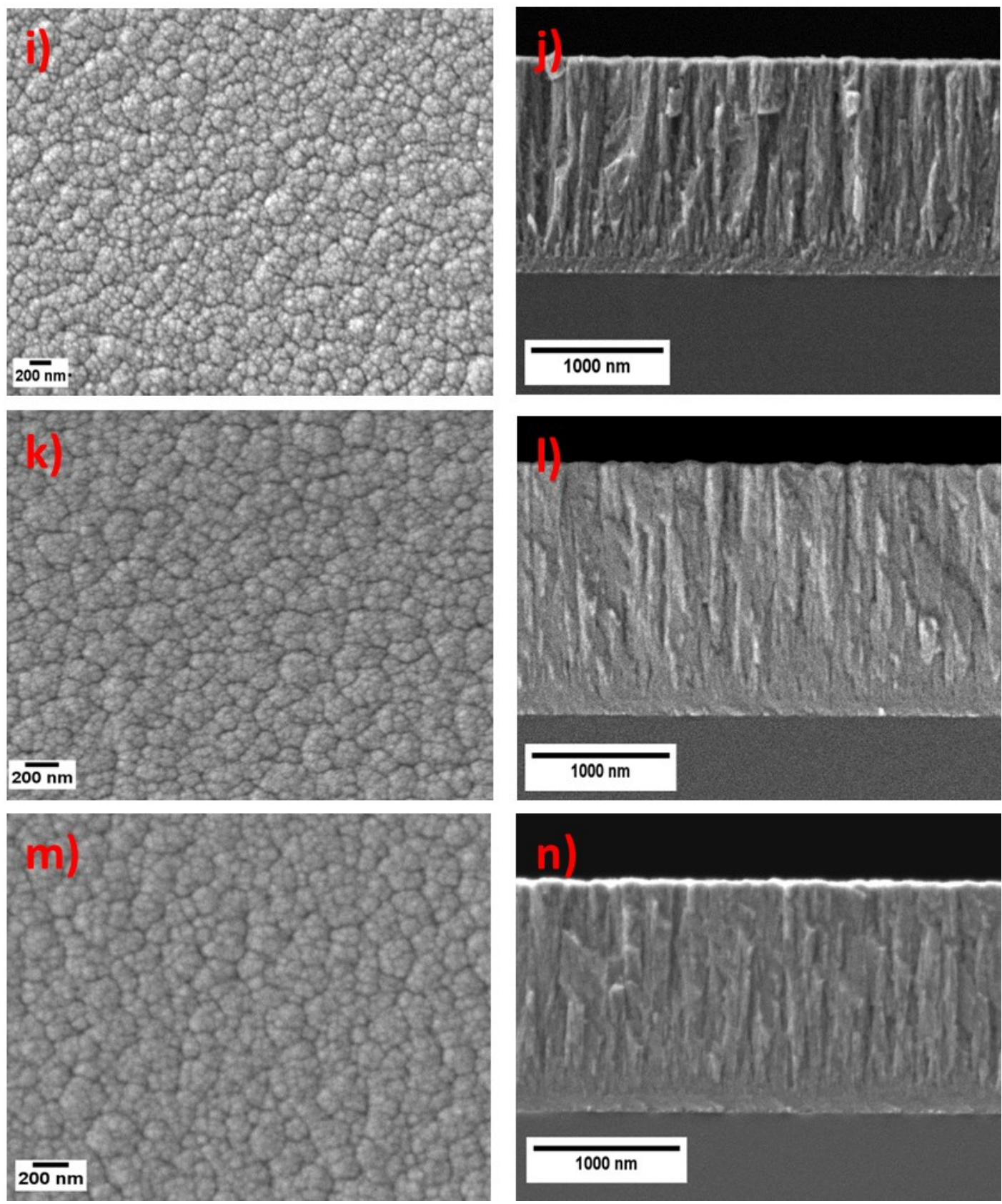

Figure 10: SEM micrographs of surface $(a, c, e, g, i, k, m)$ and cross-section morphologies $(b, d, f, h, j, l, n)$ of films deposited with increasing $N$ content of $0 \%, 18 \%, 24 \%, 28 \%, 30 \%, 35 \%$ and $37 \% N$ respectively.

\subsection{Crystal Structure}

The crystallographic structure of Mo-S-N coatings was analysed by grazing incidence XRD (GI-XRD) and it is shown in Figure 11. For the pure $\mathrm{MoS}_{2}$ coating, the XRD reflections located at $2 \theta=14^{\circ}, 33^{\circ}, 58^{\circ}$, and $60^{\circ}$ indicated that the pattern was similar to typical sputtered TMDs (for $\mathrm{MoS}_{2}-\mathrm{ICDD} 00-037-1492$ ). The peak detected at $\sim 14^{\circ}$, 
corresponding to the (002) planes, displayed very weak signals. The broad peak observed from $33^{\circ}-45^{\circ}$, with an extended shoulder, is related to the (100) and (10L) planes. These observations were in accordance with the work of Weise et al. [55] who for the first time introduced the turbostratic stacking of the $(10 \mathrm{~L})$ planes $(\mathrm{L}=1,2,3,4, \ldots)$. The low (002)/ (100) peak intensity ratio is attributed to the deposition rate as it can make a considerable effect on the orientation of the crystals in sputtered coatings. (002) planes have a high desorption rate if the deposition rate of the coatings is $15 \mathrm{~nm} / \mathrm{min}$ and above. With $\sim 15 \mathrm{~nm} / \mathrm{min}$, the deposition rate of second (002) layer becomes higher than the desorption rate of the first layer and thus (002) planar growth occurs. Here, the deposition rate was much higher $(\sim 51 \mathrm{~nm} / \mathrm{min})$ which was optimum for the (100) planar growth as compared to the $(002)[48,56]$.

Incorporation of nitrogen atoms into the $\mathrm{MoS}_{2}$ coatings, during deposition, led to significant changes in their crystal structure. Mo-S-N films with the lowest nitrogen content of about 18 at. \% showed some vestiges of the presence of (100) and (110) planes but the (002) peaks totally disappeared behaving similar to pure coatings. As the nitrogen incorporation was increased to 24 at. $\%$ and 28 at. $\%$ the intensity of (100) peak was further reduced. It has been previously reported that nitrogen can either get trapped in the basal planes of chalcogenides [57] or can replace the chalcogen atom [58] causing short-range disorder in the atomic structure. So, either of the mechanisms might be responsible for disrupting the organized growth and structure of $\mathrm{MoS}_{2}$ crystals. Then at 30 at. $\%$ of $\mathrm{N}$ and above, the coatings were completely XRD amorphous and without any evidences of the crystalline $\mathrm{MoS}_{2}$ peaks. Further increments in nitrogen doping yielded similar amorphous structures as shown by XRD spectra.

Overall, the results obtained were in disagreement with the work of Zhang et. al. [31] where the amorphousness was observed with 18 at. \% of the nitrogen doping. This difference is attributed to the deposition approach as in our case; the substrates face the $\mathrm{MoS}_{2}$ target alternating with the additional plasma source. This means that when the substrates are in-front of the $\mathrm{MoS}_{2}$ target, the nitrogen effect is a bit lower and thus the $\mathrm{MoS}_{2}$ crystallinity was observed. As the nitrogen content (or flow) in the chamber increases, the freedom for $\mathrm{MoS}_{2}$ to form crystals is hindered and, therefore, the coatings become completely amorphous. The tiny peak at $31^{\circ}$ on Mo-S-N coating (35 at. \% N) could correspond to the MoN structure, underneath the coating in the interlayer zone as mentioned above, detected due to the lower thickness of the film. 


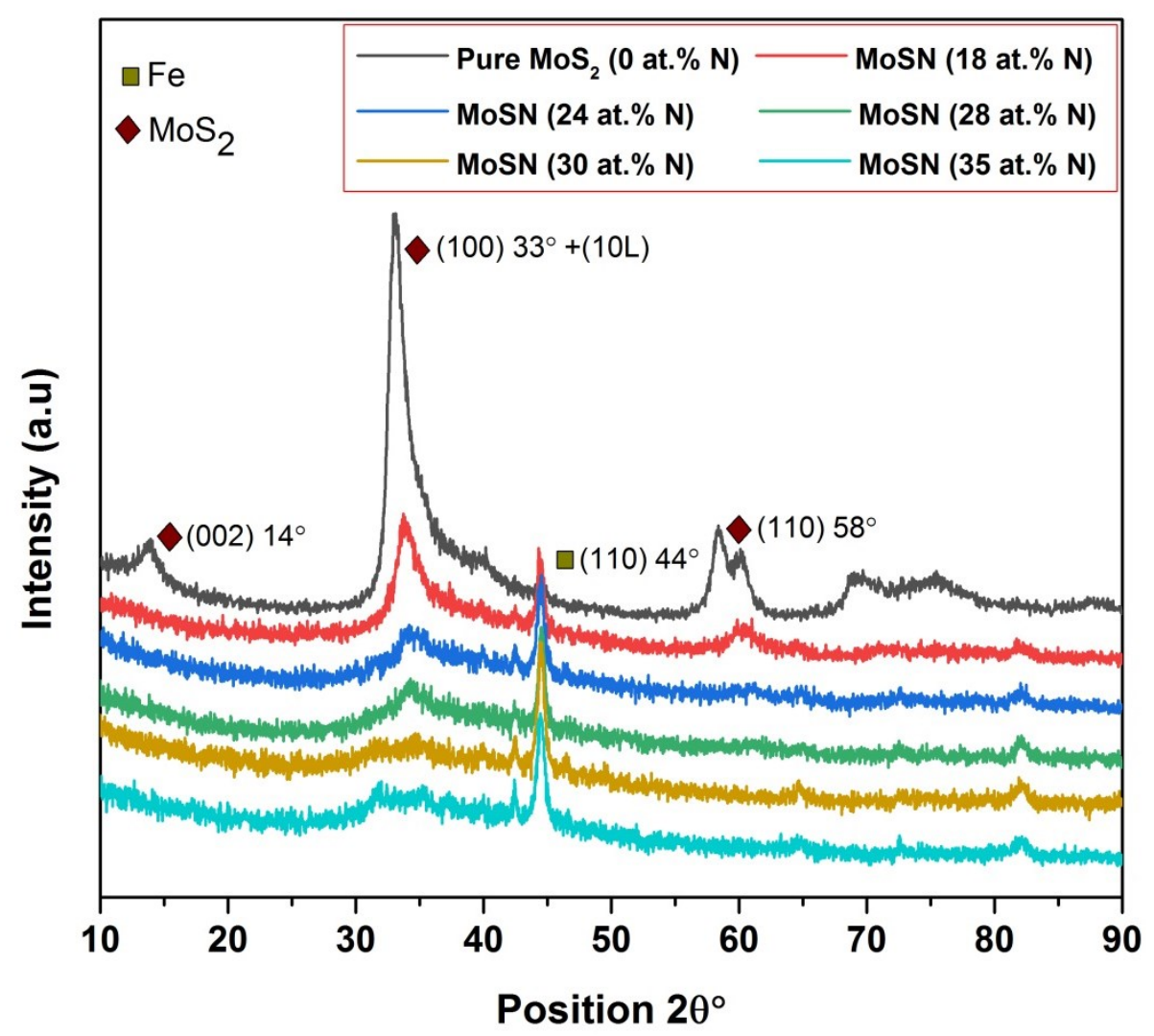

Figure 11: X-ray diffraction patterns of the coatings.

\subsection{Nanostructure}

In order to observe the effects of nitrogen doping on the $\mathrm{MoS}_{2}$ coatings, the lamella prepared from three different zones of the selected coating (with 30 at. \% $\mathrm{N}$ ) was imaged in cross-section via TEM. Figure 12 shows the obtained HR-TEM micrographs. We observed an amorphous nature of the coating, especially towards the top of the film with very few traces of the nanocrystalline lamellar $\mathrm{MoS}_{2}$. Towards the substrate interface, a combination of amorphous regions and regions with randomly oriented $\mathrm{MoS}_{2}$ platelets was observed. The coating was dense (agreeing with SEM results) and showed a dendritic nanostructure throughout the thickness of the film. The columnar features were shown to be S-rich and hence provided the conditions for the localised crystallisation of $\mathrm{MoS}_{2}$ lamellae. These few traces and small sizes were the reason that $\mathrm{MoS}_{2}$ crystalline peaks were absent in XRD analysis of this coating. 

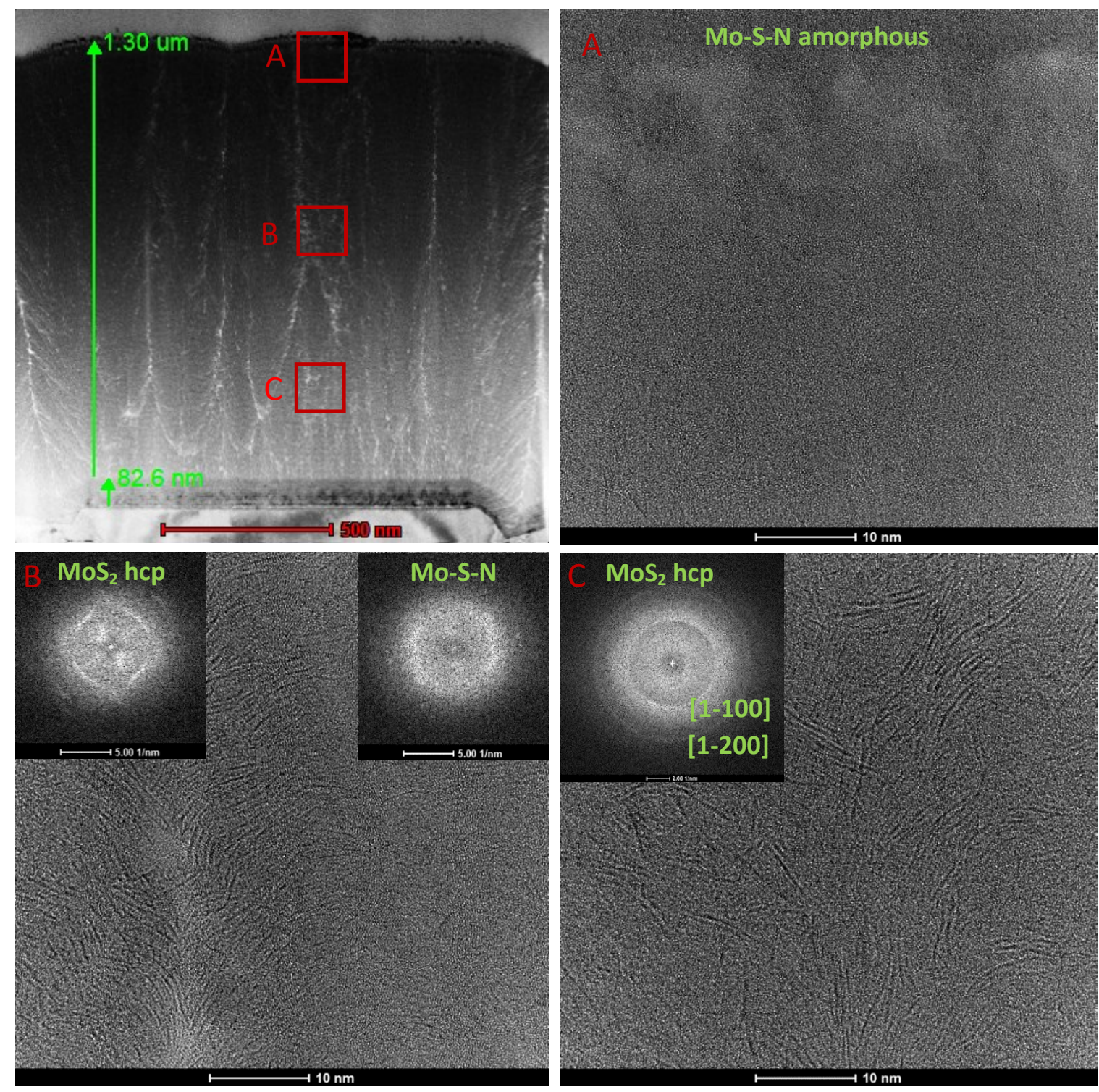

Figure 12: Microstructure of the as-deposited Mo-S-N (30 at. \% N) film with the corresponding FFT patterns are shown in insets.

\section{DISCUSSIONS}

Mo-S-N coatings were deposited by single-target DC magnetron sputtering with pulsed DC substrate bias in a planetary rotating semi-industrial machine with an additional secondary plasma source. The importance of secondary plasma source was well established for the deposition of Mo-S-N coatings to develop a novel deposition condition meant for obtaining distinctive properties. The additional secondary plasma source serves the following functions; (i) it creates low argon pressure plasma which is used to etch the steel. During this etching process, the oxides on the surface are 
removed from the ion bombardment resulting in the contaminant-free surface promoting a better adhesion of the coatings. (ii) During the coating process, it is used to vary the ion to neutral ratio of the species arriving to the substrates. (iii) The plasma density or current density can be tuned at the substrate by adjusting the plasma source power. With the help of this source, the nitrogen content in the coating was also enhanced for any particular flow of nitrogen gas into the chamber. Another important step was to obtain a highly degassed chamber prior to deposition. Heating at $150{ }^{\circ} \mathrm{C}$ for 5 hours along with pumping made the chamber free of $\mathrm{H}_{2} \mathrm{O}$ on either the substrates or over the chamber walls. The oxygen content measured in the coatings was very low compared to what other researchers found in their coatings (50\% lesser). This semi-industrial PVD machine has a large capacity of keeping many samples at a time which will rotate inside the chamber passing alternately in front of the target and the additional independent secondary plasma source. This allows the deposition process to achieve homogeneity over many samples/substrates kept in a single batch.

In this study, along with the doping of nitrogen with $\mathrm{MoS}_{2}$, an attempt was made to improve the coating adhesion to steel substrates which is one of the drawbacks for such coatings in industries. Moreover, an innovative strategy is being applied to improve the adhesion without the use of any third element metallic interlayer (e.g. Ti or Cr).

The deposition process started (after heating with pumping and etching) with making a metal-metal bonding with steel using the only target of $\mathrm{MoS}_{2}$. A thin Mo rich layer was created with high ion energy and high ion bombardment resulting in preferential re-sputtering of sulphur from the growing film leaving just a Mo- rich layer. Later, nitrogen was introduced which created a MoN (S deficient) layer. Due to the alternating between target and secondary plasma source, a multilayer feature made of varying nitrogen contents existed, as observed in figure 5. The ion bombardment also contributed to further incorporation of nitrogen in the coatings. Following this, the ion energy was reduced in order to keep sulphur in the coatings in the presence of nitrogen in the plasma. This was made to distort the formation of crystalline $\mathrm{MoS}_{2}$ thus, preventing exfoliation/delamination within coatings. The coatings were deposited at $50 \mathrm{~V}$ substrate bias for 2 hours after 20 minutes of the novel gradient layer.

The coating integrity was tested using the scratch test which validates the strategy employed to improve the adhesion. For the case of coating with novel gradient layers, the adhesion failure limit was beyond the tested range $(>80 \mathrm{~N})$. Even the Mo-S-N 
coating without the novel gradient layer showed some increase in the adhesion failure limit compared to the pure $\mathrm{MoS}_{2}$ coatings. Alloying with nitrogen and using the novel gradient layer, the cohesive failure limit had a 10 fold increase compared to pure $\mathrm{MoS}_{2}$ coatings (Table 1).Cohesive failures were identified by the initial flaking of the surface. The improvement was attributed to the prevention of any exfoliation due to the amorphousness of the Mo-S-N coatings.

The composition of the coatings had a good correlation with the structure. For the case of $\mathrm{MoS}_{2}(\mathrm{~N} 0)$ coating, the surface and cross-section images presented in Figure 10 ( $a$ and $b$ ), revealed a porous morphology. This type of coating morphology showed preferential orientation of grains in (100) direction than (002) as seen in figure 11 of XRD spectra. The crystalline anisotropy of hexagonal $\mathrm{MoS}_{2}$ contributes to the formation of fibrous-needle or platelet-like structures. It is very well known that longer grains cause shadowing effect which in-turn can create porosity during the rotation of the substrate.

For the MoSN10 coating (18 at. \% of $\mathrm{N}$ ), a diminution of the size of platelets is observed in Figure $10(c$ and $d)$. The incorporation of nitrogen provided disorder in the atomic structure of Mo and $\mathrm{S}$ and triggered a grain refinement process. The observations are supported by the XRD analysis presented in Figure 11. The intensity of the characteristic (100) peak for MoSN10 coating decreases, which indicated a disruption in the nanostructure of the coating when compared to pure $\mathrm{MoS}_{2}$ coating. The presence of nanostructure, gave rise to more compact coatings, thus steeply decreasing the thickness with nitrogen doping. The decrease in the deposition rate is also due to the decrease of the sputtering yield of Mo and S in the reactive atmosphere. This overall leads to a decrease in S/Mo ratio due to the incorporation of nitrogen into coatings. As the nitrogen ions are bombarding induced by the secondary plasma source, they participate in the removal of sulphur atoms and their replacement or get sub-planted in interstitial positions in the $\mathrm{MoS}_{2}$ structure. Nitrogen alloying thus induces amorphousness in the $\mathrm{MoS}_{2}$ coatings.

Further addition of nitrogen to 28 at. $\%$ ( $30 \mathrm{sccm} \mathrm{N}_{2}$ flow), results in the formation of amorphous and dense coating as well as in the drastic reduction of the XRD peak intensity. Figure $10(g$ and $h$ ) also show less porosity and highly compact coating. All further increase in nitrogen content has led to amorphous coatings which are in good agreement with the structure and surface morphology. Thus, nitrogen alloyed coatings 
showed a reduced thickness compared to pure $\mathrm{MoS}_{2}$ coating. Though some sulphur atom could have been replaced by nitrogen, a substantial amount of sulphur was still retained within the coating even for 37 at. \% of N (MoSN60 coating). In this case, the minimum S/Mo ratio was observed (1.25).

To understand the chemical bonding mechanism within the coating, XPS revealed quite interesting results. Even for 35 at. \% of N (MoSN50 coating) the Mo-S peak $(228.3 \mathrm{eV})$ was dominant over Mo-N peak $(229.0 \mathrm{eV})$. Also, the S2s peak at $226.3 \mathrm{eV}$ showed the presence of S-S bonds whereas N-N bonds were detected at $397.5 \mathrm{eV}$. This reveals that a good amount of $\mathrm{MoS}_{2}$ compound was formed even for highly doped films. The formation of such bonds could be due to the deposition process, to the use of alternating magnetron sputtering and secondary plasma source which incorporates $\mathrm{N} / \mathrm{Mo} / \mathrm{S}$ and $\mathrm{N}$ (in small quantity), respectively. Thus, a process of deposition of $\mathrm{MoS}_{2}$ takes place, after bombardment some $\mathrm{S}$ is re-sputtered and $\mathrm{N}$ is incorporated. Thereby, only some Mo-S bonds are replaced with Mo-N bonds at secondary plasma source. This also corroborates with the chemical composition where S/Mo ratio was 1.26.

The ion bombardment from plasma source also promotes desorption of impurities, thereby the $\mathrm{C}$ (not shown) and $\mathrm{O}$ contents in the coating is found to be reduced in comparison to the coating without the use of plasma source as seen in table 2 . The additional plasma source plays a very crucial role in desorption of impurities, the incorporation of nitrogen by bombardment and the reorganises the surface of the coating to prevent voids. Therefore, the nitrogen is incorporated into the coating by two means: (i) due to the normal sputtering process in reactive mode in nitrogen-containing plasma and, (ii) by additional $\mathrm{N}$ ion bombardment by the secondary plasma source. Nitrogen can either get entrapped between the basal planes [57] or can replace the chalcogen atom [58] causing disorder in the atomic placement. Komsa et. al. [59] showed, based on theoretical predictions and experiments, that it was possible to dope $\mathrm{MoS}_{2}$ by filling the vacancies created by the electron beam with impurity atoms. It was feasible to have a $\mathrm{MoS}_{2}$ sheet with S vacancy filled in by an isolated atom of N. Later, Dolui et.al. [60] described some possible doping strategies for $\mathrm{MoS}_{2}$ monolayers, using density functional theory, by a first substitutional doping at both the Mo and S sites. They reported that the best strategy would be to grow S-poor films and, then, filling the vacancies with an appropriate atom, such as N. Due to the high formation energy of the vacancy, $\mathrm{N}$ substitution is energetically favoured since that energy is largely dependent 
on the growth conditions. Based on this work, the highest nitrogen content films is achieved by using high ion bombardment with the secondary plasma source, high S/Mo ratio, should have a structure consisting of a Mo-S-N compound with Mo bonded to S and N. Such a compound would be amorphous in nature.

Finally, it is safe to say that at least $30 \%$ nitrogen content can provide a complete amorphous structure. Thus, in our case, the structure of Mo-S-N coatings are crystalline or nanocrystalline from $0-28$ at. $\% \mathrm{~N}$ and changes to amorphous above 28 at.\% N. Such nitrogen-doped coatings have a high potential for projecting impressive tribological properties in vacuum and humid air.

\section{CONCLUSIONS}

In this study, Mo-S-N coatings were deposited using a semi-industrial DC magnetron sputtering apparatus with a single target of $\mathrm{MoS}_{2}$ and planetary rotating substrate holder on Si (100) and M2 steel substrates. The chemical composition, morphology, structure and chemical bonding were studied as a function of the Ncontent of Mo-S-N coatings. An innovative novel gradient layer was synthesised to improve the adhesion of the coatings with the steel substrates having metal-metal bonding (strong bonding). Then, adhesion failure limit beyond the tested range of $80 \mathrm{~N}$ was achieved with a single $\mathrm{MoS}_{2}$ target and without the need to use any metallic interlayers (e.g. $\mathrm{Ti}$ or $\mathrm{Cr}$ ). This simplifies the depositions in the industrial environment solving a major industrial issue. The initial Lc1 representing the initial cohesive cracking/flaking of the coatings was $38 \mathrm{~N}$ for the 28 at. \% nitrogen content coating. With heating and pumping prior to etching and deposition, it was possible to attain very low oxygen content in coatings, less than 1 at. \%. The structure of the coatings changed with the incorporation of nitrogen. The coatings with less than 30 at. \% $\mathrm{N}$ was nanocrystalline; for higher contents coatings became XRD amorphous. The morphology was increasingly more compact with the incorporation of nitrogen. HRTEM also confirmed the presence of amorphism in high $\mathrm{N}$-content coatings. The S/Mo ratio was also improved and maintained to 1.25 for the highest $\mathrm{N}$ incorporation ( 37 at. $\% \mathrm{~N})$. The ideal atomic arrangement based on the above results would be that nitrogen was incorporated in a ternary compound, such as Mo-S-N, with Mo-N and Mo-S bonds. These coatings with enhanced adhesion, high S/Mo ratio, very high compactness and 
low contaminant contents have great potential to show high hardness and other interesting mechanical and tribological properties.

\section{ACKNOWLEDGEMENTS}

This project has received funding from the European Union Horizon 2020 research and innovation programme under grant agreement No. 721642: SOLUTION.

The electron microscopy imaging was performed with the support of the South of England Analytical Electron Microscope (EP/K040375/1), within the David Cockayne Centre for Electron Microscopy, Department of Materials, University of Oxford. Alongside financial support provided by the Henry Royce Institute (EP/R010145/1) and CEITEC Nano Research Infrastructure (ID LM2015041, MEYS CR, 2016-2019), CEITEC Brno University of Technology.

The authors would also like to thank funding from CEMMPRE UID/EMS/00285/2019 [co-financed via FEDER and FCT (COMPETE)]. 


\section{References}

[1] W.E. Jamison, S.L. Cosgrove, Friction Characteristics of Transition-Metal Disulfides and Diselenides, A S L E Trans. 14 (1971) 62-72. https://doi.org/10.1080/05698197108983228.

[2] Y. Zhao, Y. Zhang, Z. Yang, Y. Yan, K. Sun, Synthesis of MoS2and MoO2for their applications in $\mathrm{H} 2$ generation and lithium ion batteries: a review, Sci. Technol. Adv. Mater. 14 (2013) 43501. https://doi.org/10.1088/14686996/14/4/043501.

[3] T. Polcar, A. Cavaleiro, Review on self-lubricant transition metal dichalcogenide nanocomposite coatings alloyed with carbon, Surf. Coat. Technol. 206 (2011) 686-695. https://doi.org/10.1016/j.surfcoat.2011.03.004.

[4] K. Ren, M.L. Sun, Y. Luo, S.K. Wang, J. Yu, W.C. Tang, First-principle study of electronic and optical properties of two-dimensional materials-based heterostructures based on transition metal dichalcogenides and boron phosphide, Appl. Surf. Sci. 476 (2019) 70-75. https://doi.org/10.1016/j.apsusc.2019.01.005.

[5] Z. Cui, K. Ren, Y. Zhao, X. Wang, H. Shu, J. Yu, W. Tang, M. Sun, Electronic and optical properties of van der Waals heterostructures of g-GaN and transition metal dichalcogenides, Appl. Surf. Sci. 492 (2019) 513-519. https://doi.org/10.1016/j.apsusc.2019.06.207.

[6] J.S. Zabinski, M.S. Donley, S. V Prasad, N.T. McDevitt, Synthesis and characterization of tungsten disulphide films grown by pulsed-laser deposition, J. Mater. Sci. 29 (1994) 4834-4839. https://doi.org/10.1007/BF00356530.

[7] H. Waghray, T.-S. Lee, B.J. Tatarchuk, A study of the tribological and electrical properties of sputtered and burnished transition metal dichalcogenide films, Surf. Coatings Technol. 76-77 (1995) 415-420. https://doi.org/https://doi.org/10.1016/0257-8972(95)02564-2.

[8] M.F. Cardinal, P.A. Castro, J. Baxi, H. Liang, F.J. Williams, Characterization and frictional behavior of nanostructured Ni-W-MoS2 composite coatings, Surf. Coatings Technol. 204 (2009) 85-90. https://doi.org/https://doi.org/10.1016/j.surfcoat.2009.06.037. 
[9] G. Stachowiak, A.W. Batchelor, Engineering tribology, Butterworth-Heinemann, 2013.

[10] A.R. Lansdown, Molybdenum Disulphide Lubrication, Elsevier, 1999. https://doi.org/10.1108/ilt.2000.01852aae.001.

[11] J. Moser, F. Lévy, Crystal reorientation and wear mechanisms in MoS2 lubricating thin films investigated by TEM, J. Mater. Res. 8 (1993) 206-213. https://doi.org/10.1017/s0884291400120539.

[12] I.L. Singer, S. Fayeulle, P.D. Ehni, Wear behavior of triode-sputtered MoS 2 coatings in dry sliding contact with steel and ceramics, Wear. 195 (1996) 7-20. https://doi.org/https://doi.org/10.1016/0043-1648(95)06661-6.

[13] N.M. Renevier, N. Lobiondo, V.C. Fox, D.G. Teer, J. Hampshire, Performance of MoS2/metal composite coatings used for dry machining and other industrial applications, Surf. Coatings Technol. 123 (2000) 84-91. https://doi.org/10.1016/S0257-8972(99)00424-7.

[14] W. Lauwerens, J. Wang, J. Navratil, E. Wieërs, J. D’haen, L.M. Stals, J.P. Celis, Y. Bruynseraede, Humidity resistant MoSx films prepared by pulsed magnetron sputtering, Surf. Coatings Technol. 131 (2000) 216-221. https://doi.org/https://doi.org/10.1016/S0257-8972(00)00796-9.

[15] P. Wang, L. Qiao, J. Xu, W. Li, W. Liu, Erosion Mechanism of MoS2-Based Films Exposed to Atomic Oxygen Environments, ACS Appl. Mater. Interfaces. 7 (2015) 12943-12950. https://doi.org/10.1021/acsami.5b02709.

[16] X. Ding, X.T. Zeng, X.Y. He, Z. Chen, Tribological properties of Cr- and Tidoped MoS2 composite coatings under different humidity atmosphere, Surf. Coatings Technol. 205 (2010) 224-231. https://doi.org/https://doi.org/10.1016/j.surfcoat.2010.06.041.

[17] V. Rigato, G. Maggioni, A. Patelli, D. Boscarino, N.M. Renevier, D.G. Teer, Properties of sputter-deposited MoS2/metal composite coatings deposited by closed field unbalanced magnetron sputter ion plating, Surf. Coatings Technol. 131 (2000) 206-210. https://doi.org/https://doi.org/10.1016/S02578972(00)00797-0.

[18] F. Bülbül, İ. Efeoğlu, Synergistic effect of bias and target currents for magnetron 
sputtered MoS2-Ti composite films, Mater. Test. 58 (2016) 471-474. https://doi.org/10.3139/120.110870.

[19] J.J. Nainaparampil, A.R. Phani, J.E. Krzanowski, J.S. Zabinski, Pulsed laserablated MoS2-Al films: friction and wear in humid conditions, Surf. Coatings Technol. 187 (2004) 326-335.

https://doi.org/https://doi.org/10.1016/j.surfcoat.2004.02.043.

[20] D.G. Teer, J. Hampshire, V. Fox, V. Bellido-Gonzalez, The tribological properties of MoS2/metal composite coatings deposited by closed field magnetron sputtering, Surf. Coatings Technol. 94-95 (1997) 572-577. https://doi.org/https://doi.org/10.1016/S0257-8972(97)00498-2.

[21] S. Gangopadhyay, R. Acharya, A.K. Chattopadhyay, S. Paul, Effect of substrate bias voltage on structural and mechanical properties of pulsed DC magnetron sputtered TiN-MoSx composite coatings, Vacuum. 84 (2010) 843-850. https://doi.org/https://doi.org/10.1016/j.vacuum.2009.11.010.

[22] B.C. Stupp, Synergistic effects of metals co-sputtered with MoS2, Thin Solid Films. 84 (1981) 257-266. https://doi.org/https://doi.org/10.1016/00406090(81)90023-7.

[23] J.R. Lince, H.I. Kim, P.M. Adams, D.J. Dickrell, M.T. Dugger, Nanostructural, electrical, and tribological properties of composite $\mathrm{Au}-\mathrm{MoS} 2$ coatings, Thin Solid Films. 517 (2009) 5516-5522. https://doi.org/https://doi.org/10.1016/j.tsf.2009.03.210.

[24] T. Spalvins, Frictional and morphological properties of Au $\square$ MoS2 films sputtered from a compact target, Thin Solid Films. 118 (1984) 375-384. https://doi.org/https://doi.org/10.1016/0040-6090(84)90207-4.

[25] S. Mikhailov, A. Savan, E. Pflüger, L. Knoblauch, R. Hauert, M. Simmonds, H. Van Swygenhoven, Morphology and tribological properties of metal (oxide)MoS2 nanostructured multilayer coatings, Surf. Coatings Technol. 105 (1998) 175-183. https://doi.org/https://doi.org/10.1016/S0257-8972(98)00483-6.

[26] J.S. Zabinski, M.S. Donley, S.D. Walck, T.R. Schneider, N.T. Mcdevitt, The Effects of Dopants on the Chemistry and Tribology of Sputter-Deposited MoS2 Films, Tribol. Trans. 38 (1995) 894-904. 
https://doi.org/10.1080/10402009508983486.

[27] M.R. Hilton, R. Bauer, S. V Didziulis, M.T. Dugger, J.M. Keem, J. Scholhamer, Structural and tribological studies of MoS2 solid lubricant films having tailored metal-multilayer nanostructures, Surf. Coatings Technol. 53 (1992) 13-23. https://doi.org/https://doi.org/10.1016/0257-8972(92)90099-V.

[28] K.J. Wahl, D.N. Dunn, I.L. Singer, Wear behavior of Pb-Mo-S solid lubricating coatings, Wear. 230 (1999) 175-183.

https://doi.org/https://doi.org/10.1016/S0043-1648(99)00100-3.

[29] X. Liu, G.J. Ma, G. Sun, Y.P. Duan, S.H. Liu, MoSx-Ta composite coatings on steel by d.c magnetron sputtering, Vacuum. 89 (2013) 203-208. https://doi.org/https://doi.org/10.1016/j.vacuum.2012.05.013.

[30] D. Jianxin, S. Wenlong, Z. Hui, Z. Jinlong, Performance of PVD MoS2/Zrcoated carbide in cutting processes, Int. J. Mach. Tools Manuf. 48 (2008) 15461552. https://doi.org/https://doi.org/10.1016/j.ijmachtools.2008.06.009.

[31] X. Zhang, L. Qiao, L. Chai, J. Xu, L. Shi, P. Wang, Structural, mechanical and tribological properties of Mo-S-N solid lubricant films, Surf. Coatings Technol. 296 (2016) 185-191. https://doi.org/10.1016/j.surfcoat.2016.04.040.

[32] H. Nyberg, J. Sundberg, E. Särhammar, F. Gustavsson, T. Kubart, T. Nyberg, U. Jansson, S. Jacobson, Extreme friction reductions during initial running-in of WS-C-Ti low-friction coatings, Wear. 302 (2013) 987-997. https://doi.org/https://doi.org/10.1016/j.wear.2013.01.065.

[33] A.A. Voevodin, J.P. O’Neill, J.S. Zabinski, WC/DLC/WS2 nanocomposite coatings for aerospace tribology, Tribol. Lett. 6 (1999) 75-78. https://doi.org/10.1023/A:1019163707747.

[34] M. Evaristo, T. Polcar, A. Cavaleiro, Synthesis and properties of W-Se-C coatings deposited by PVD in reactive and non-reactive processes, Vacuum. 83 (2009) 1262-1265. https://doi.org/https://doi.org/10.1016/j.vacuum.2009.03.030.

[35] A. Nossa, A. Cavaleiro, Tribological Behaviour of N(C)-Alloyed W-S Films, Tribol. Lett. 28 (2007) 59-70. https://doi.org/10.1007/s11249-007-9248-3.

[36] L. Isaeva, J. Sundberg, S. Mukherjee, C.J. Pelliccione, A. Lindblad, C.U. Segre, U. Jansson, D.D. Sarma, O. Eriksson, K. Kádas, Amorphous W-S-N thin films: 
The atomic structure behind ultra-low friction, Acta Mater. 82 (2015) 84-93. https://doi.org/10.1016/j.actamat.2014.08.043.

[37] J. Sundberg, H. Nyberg, E. Särhammar, T. Nyberg, S. Jacobson, U. Jansson, Influence of composition, structure and testing atmosphere on the tribological performance of W-S-N coatings, Surf. Coatings Technol. 258 (2014) 86-94. https://doi.org/10.1016/j.surfcoat.2014.09.061.

[38] P. Mutafov, M. Evaristo, A. Cavaleiro, T. Polcar, Structure, mechanical and tribological properties of self-lubricant W-S-N coatings, Surf. Coatings Technol. 261 (2015) 7-14. https://doi.org/10.1016/j.surfcoat.2014.11.074.

[39] A. Nossa, A. Cavaleiro, Chemical and physical characterization of C(N)-doped W-S sputtered films, J. Mater. Res. 19 (2004) 2356-2365. https://doi.org/DOI: 10.1557/JMR.2004.0293.

[40] A. Nossa, A. Cavaleiro, The influence of the addition of $\mathrm{C}$ and $\mathrm{N}$ on the wear behaviour of W-S-C/N coatings, Surf. Coatings Technol. 142-144 (2001) 984991. https://doi.org/10.1016/S0257-8972(01)01249-X.

[41] Z. Daming, L. Jiajun, Z. Baoliang, L. Wenzhi, A study of the friction and wear performance of MoSx thin films produced by ion beam enhanced deposition and magnetron sputtering, Wear. 210 (1997) 45-49. https://doi.org/https://doi.org/10.1016/S0043-1648(97)00039-2.

[42] V.Y. Fominski, V.N. Nevolin, R.I. Romanov, I. Smurov, Ion-assisted deposition of MoSx films from laser-generated plume under pulsed electric field, J. Appl. Phys. 89 (2001) 1449-1457. https://doi.org/10.1063/1.1330558.

[43] A. Nossa, A. Cavaleiro, Mechanical behaviour of W-S-N and W-S-C sputtered coatings deposited with a Ti interlayer, Surf. Coatings Technol. 163-164 (2003) 552-560. https://doi.org/10.1016/S0257-8972(02)00622-9.

[44] et al. D. Camino, D. Teer, J. Von Stebut, M. Gee, N. Jennett, J. Banks, Scratch adhesion testing of coated surfaces-Challenges and new directions, Adhes. Meas. Film. \\& Coatings. 2.2 (2001).

[45] A. Nossa, A. Cavaleiro, N.J.M. Carvalho, B.J. Kooi, J.T.M. De Hosson, On the microstructure of tungsten disulfide films alloyed with carbon and nitrogen, Thin Solid Films. 484 (2005) 389-395. https://doi.org/10.1016/j.tsf.2005.02.018. 
[46] G. Eda, H. Yamaguchi, D. Voiry, T. Fujita, M. Chen, M. Chhowalla, Photoluminescence from chemically exfoliated MoS 2, Nano Lett. 11 (2011) 5111-5116. https://doi.org/10.1021/nl201874w.

[47] M. Donarelli, F. Bisti, F. Perrozzi, L. Ottaviano, Tunable sulfur desorption in exfoliated MoS2 by means of thermal annealing in ultra-high vacuum, Chem. Phys. Lett. 588 (2013) 198-202. https://doi.org/https://doi.org/10.1016/j.cplett.2013.10.034.

[48] T. Bin Yaqub, T. Vuchkov, P. Sanguino, T. Polcar, Comparative Study of DC and RF Sputtered MoSe 2 Coatings Containing Carbon - An Approach to Optimize Stoichiometry , Microstructure , Crystallinity and Hardness, (2020) 116. https://doi.org/10.3390/coatings10020133.

[49] T. Hudec, M. Mikula, L. Satrapinskyy, T. Roch, M. Truchlý, P. Švec, T. Huminiuc, T. Polcar, Structure, mechanical and tribological properties ofMo-S-N solid lubricant coatings, Appl. Surf. Sci. (2019). https://doi.org/10.1016/j.apsusc.2019.03.294.

[50] Z. Han, J. Tian, Q. Lai, X. Yu, G. Li, Effect of N2 partial pressure on the microstructure and mechanical properties of magnetron sputtered $\mathrm{CrNx}$ films, Surf. Coatings Technol. 162 (2003) 189-193. https://doi.org/https://doi.org/10.1016/S0257-8972(02)00667-9.

[51] NIST X-ray Photoelectron Spectroscopy Database Version 4.1, Natl. Inst. Stand. Technol. Gaithersbg. (2012). http://srdata.nist.gov/xps/.

[52] I. Jauberteau, A. Bessaudou, R. Mayet, J. Cornette, L.J. Jauberteau, P. Carles, T. Merle-Méjean, Molybdenum Nitride Films: Crystal Structures, Synthesis, Mechanical, Electrical and Some Other Properties, Coatings . 5 (2015). https://doi.org/10.3390/coatings5040656.

[53] F. Niefind, J. Djamil, W. Bensch, B.R. Srinivasan, I. Sinev, W. Grünert, M. Deng, L. Kienle, A. Lotnyk, M.B. Mesch, J. Senker, L. Dura, T. Beweries, Room temperature synthesis of an amorphous MoS2 based composite stabilized by Ndonor ligands and its light-driven photocatalytic hydrogen production, RSC Adv. 5 (2015) 67742-67751. https://doi.org/10.1039/C5RA14438H.

[54] T. Polcar, A. Cavaleiro, Self-adaptive low friction coatings based on transition 
metal dichalcogenides, Thin Solid Films. 519 (2011) 4037-4044.

https://doi.org/10.1016/j.tsf.2011.01.180.

[55] G. Weise, N. Mattern, H. Hermann, A. Teresiak, I. Ba, W. Bru, Preparation, structure and properties of MoSx films, Thin Soli. 298 (1997) 98-106. https://doi.org/10.1016/S0040-6090(96)09165-1.

[56] C. Muratore, A.A. Voevodin, Control of molybdenum disul fi de basal plane orientation during coating growth in pulsed magnetron sputtering discharges, Thin Solid Films. 517 (2009) 5605-5610. https://doi.org/10.1016/j.tsf.2009.01.190.

[57] K.D. Rasamani, F. Alimohammadi, Y. Sun, Interlayer-expanded MoS 2, Mater. Today. 20 (2017). https://doi.org/10.1016/j.mattod.2016.10.004.

[58] P.D. Fleischauer, J.R. Lince, Comparison of oxidation and oxygen substitution in MoS2solid film lubricants, Tribol. Int. 32 (1999) 627-636. https://doi.org/10.1016/S0301-679X(99)00088-2.

[59] H.P. Komsa, J. Kotakoski, S. Kurasch, O. Lehtinen, U. Kaiser, A. V. Krasheninnikov, Two-dimensional transition metal dichalcogenides under electron irradiation: Defect production and doping, Phys. Rev. Lett. 109 (2012) 1-5. https://doi.org/10.1103/PhysRevLett.109.035503.

[60] K. Dolui, I. Rungger, C. Das Pemmaraju, S. Sanvito, Possible doping strategies for MoS2 monolayers: An ab initio study, Phys. Rev. B. 88 (2013) 75420. https://doi.org/10.1103/PhysRevB.88.075420. 